\title{
AB Ülkelerinin Küresel Cinsiyet Ayrımının Kadınlar Açısından Gri İlişkisel Analiz, ARAS ve COPRAS Yöntemleri ile Değerlendirilmesi
}

DOI: $10.26466 /$ opus.774845

\begin{abstract}
*
Emre Yakut*- Özlem Kuru**

${ }^{*}$ Dr. Öğr. Üyesi, Osmaniye Korkut Ata Üniversitesi, İ.I.B.F.,Osmaniye/Türkiye E-Posta: emreyakut@osmaniye.edu.tr ORCID: 0000-0002-1978-0217

**Arş. Gör., Osmaniye Korkut Ata Üniversitesi, İktisadi İdari Bilimler Fakültesi, Osmaniye/Türkiye E-Posta: ozlemkuru@osmaniye.edu.tr

ORCID: 0000-0003-0208-4781

Öz

Cinsiyet eşitsizliği, bireylerin yalnızca cinsiyetlerinden dolayı firsatlara ve kaynaklara eşit erişim sağlayamaması, önyargılardan dolayı bireysel varlı̆̆ın hissettirmekte sorun yaşaması, sağlık-eğitim gibi insani konularda diğer cinsten arka planda tutulması durumu olarak özetlenebilir. Bireylerin biyolojik özellikleri (cinsiyetleri) nedeniyle iş hayatı, eğitim, să̆lık gibi alanlarda ikinci plana atılması ülkelerde demokrasi ve ekonomi bakımından olumsuz etkiler yaratabilir. Ülkelerin bu etkileri en aza indirmeleri için global olarak yerlerini görmelerini sağlamak amactyla cinsiyet eşitsizliğini değerlendirmek üzere çeşitli çalışmalar yapılmaktadır. Bu çalışmada bahsi geçen amaç için Dünya Ekonomik Forumu (WEF-World Economic Forum) tarafindan her yıl hazırlanan Küresel Cinsiyet Ayrımı Raporu'nda (KCAR) yer alan Avrupa Birliği (AB) üye ülkelerinin cinsiyet eşitlikleri değerlendirilmiştir. 2017, 2018 ve 2020 yıllar raporlarındaki verilerden yararlanılarak 4 ana başlı altında toplam 14 kriter elde edilmiş, AB üye ülkelerinin kendi aralarında sıralamalarını gerçekleştirmek üzere Gri ilişkisel analiz (GIA), ARAS ve COPRAS yöntemleri kullanılmıştır. Spearman Korelasyon analiziyle belirtilen döneme ilişkin yöntemler arası karşılaştırma gerçekleştirilmiş̧ir. KCAR raporuna ilişkin AB ülkelerinin cinsiyet eşitliği sıralamasına bağhl olarak GIA yönteminin ARAS ve COPRAS yöntemlerinden daha başarılı sıralama sonucu gerçekleştirdiği tespit edilmiştir.
\end{abstract}

Anahtar Kelimeler: Cinsiyet Eşitliği, Çok Kriterli Karar Verme, ARAS, COPRAS, Gri İlişkisel Analiz 


\title{
Evaluation of EU Countries in the Global Gender Gap by Grey Relational Analysis, ARAS and COPRAS Methods for Women
}

\begin{abstract}
Gender inequality can be summarized as the situation of individuals failure to provide equal access to opportunities and resources, problems with making the individual presence felt due to prejudices and keeping in the background of other sex on humanitarian issues such as health and education due to their sex. Due to the biological characteristics (genders) of individuals, the fact that they take the second place in fields such as business life, education and health may have negative effects on countries' democracy and economy. Various studies are being conducted to evaluate gender inequality in order to enable countries to see their place globally to minimize these effects. In this study, the gender inequalities of the European Union (EU) member countries, which are included in the Global Gender Gap Report prepared by the World Economic Forum every year, are evaluated. Using the data in the reports of 2017, 2018 and 2020, a total of 14 criteria were obtained under 4 main headings, and Gray relational analysis (GRA), ARAS and COPRAS methods were used to rank EU member states among themselves. A comparison between methods was made with Spearman correlation analysis for the specified period. Based on the gender equality ranking of EU countries in the The Global Gender Gap Report, GRA method was found to perform more successfully than the ARAS and COPRAS methods.
\end{abstract}

Keywords: Gender Equality, Multicriteria Decision Making, Grey Relational Analysis, ARAS, COPRAS 


\section{Giriş}

Türkçe'de günlük yaşamda üzerine düşünülmeden "cinsiyet" olarak kullanılan biyolojik özellik belirtilen terim esasında "cinsiyet" ve "toplumsal cinsiyet" terimlerinin her ikisini de ifade etmektedir. Cinsiyet (İngilizce'de "sex"), bireyin doğumdan itibaren sahip olduğu dişi veya er kategorisinde olma özelliğini ifade etmektedir. Ancak toplumsal cinsiyet (İngilizce' de "gender") bireyin sahip olduğu cinsiyete (dahil olduğu kategoriye) dayalı olarak toplum tarafından bireyden beklentilerini ifade etmekte, başka bir ifadeyle bireyin toplumdaki yerini tanımlamaktadır (Vatandaş, 2007, s.31).

Toplumsal cinsiyet terimi Ann Oakley tarafından literatüre kazandırılmıştır (Şafak Uzun, 2019, s.16). Ann Oakley (1985, s.16) toplumsal cinsiyet terimini, cinsiyetin kültür ile bağlantılı olarak maskülen ve feminen açısından bir sosyal sınıflandırmaya tabi tutulması olarak açıklamaktadır.

Vatandaş (2007, s.33), ayrımcılığın temelde önyargıdan kaynaklandığını belirtmektedir. Cinsiyet ayrımcılığı da çeşitli söylemler, kanaatler ve deneyimlerden kaynaklanan önyargı vasitasıyla toplumsal bir hal almaktadır. Bora (2011, s.1), toplumsal cinsiyete dayalı ayrımcılığın bireylerin cinsiyetlerine bağlı olarak rollerinin değişmez oluşunun kabul görülmesinden kaynaklandığını belirtmiştir. Oysa kabul görülen bu durumun kültüre ve zamana göre değişkenlik gösterebileceği bilinmektedir.

Toplumsal cinsiyet kavramının ortaya çımasında etkili olan, bireylere toplum tarafından yüklenen kadınlık ve erkeklik rolleri, kadınların zayıf veya narin olduğunu vurgulayan ve kadının aleyhine olan, erkeklerin üstünlügünü kabul eden bir eşitsizliğin (cinsiyet eşitsizliğinin) ortaya çıkmasında rol almaktadır (Vargel Pehlivan, 2017, s.501).

Avrupa Cinsiyet Eşitliği Enstitüsü'ne (EIGE) göre cinsiyet eşitsizliği, cinsiyetin kadınlar ve erkeklerin haklara erişimi ve yararlanmaları konusunda eşit olmayan koşullara sahip olmasının yanında klişe sosyal ve kültürel rollerin kanıksanmasıyla bireylere farklı haklar ve saygınlık belirlediği yasal, sosyal ve kültürel bir durumdur (EIGE, 2020).

Toplumlarda kabul gören ataerkil yapının bir getirisi olarak cinsiyet eşitsizliğinin daha çok kadınları etkileyen olan bir durum olduğu aşikardır. Kadınların temel ihtiyaçlara erişimi, firsatlardan ve kaynaklardan yararlanma konusunda biyolojik özellikleri nedeniyle ayrımcılık yaşaması, siyasi ve toplumsal alanda daha pasif görüntü vermesi ve daha az temsil görmesi cinsiyet 
eşitsizliğinin nedenlerindendir. Çalışma hayatı, ekonomi, eğitim, siyaset ve sağlık gibi birçok alanda cinsiyet eşitsizliğinin etkileri hissedilmektedir. Ülkelerin gelişmişlik düzeylerine göre eşitsizliğin aldığı durum değişebilmektedir. Gelişmiş ülkelerde kadınların benzer pozisyon için erkeklerle aynı ücreti alamaması, terfi aşamasında problemler yaşaması gibi sorunlara neden olan eşitsizlik, gelişmekte olan ülkelerde kadına şiddet, eğitim hakkının gözetilmemesi olarak ortaya çıkabilmektedir (Bozkaya, 2016, s.36).

Birleşmiş Milletler (UN-United Nations) Ekonomik ve Sosyal İşler Daire Başkanlığı (2019) verilerine göre dünya nüfusunun yaklaşık yüzde 49,5'i kadınlardan oluşmaktadır (Kara, 2019, s.61). Buna göre nüfusun neredeyse yarısının baskılanarak pasif bırakılması, çeşitli engeller ile üretimden uzaklaştırılmasının ülkelere etkilerinin olumsuz yönde olması anlaşılabilir bir durumdur. Üstün (2011, s.9), toplumsal cinsiyet eşitsizliğinin yalnızca kadınları ve kız çocuklarını etkileyen sosyal bir durum değil, demokratikleşme ve kalkınmanın önünde bir engel olduğunu belirtmektedir.

Cinsiyet eşitsizliğinin değerlendirilmesi için birtakım endeksler geliştirilmiştir. Bu endekslerden bazıları Küresel Cinsiyet Ayrımı Endeksi (Global Gender Gap Index, GGGI), Cinsiyet Eşitsizliği Endeksi (Gender Inequality Index, GII) ve Cinsiyete Dayalı Gelişme Endeksi (Gender Related Development Index, GDI) olarak siralanabilir (Bozkaya, 2016, s.43).

Literatürde bu endeksleri kullanarak yapılan çok sayıda çalışma yer almaktadır. Bir sonraki bölümde konu ile ilgili endekslerin ve çalışmanın yöntemlerinin kullanıldığı çalışmalardan bazıları özetlenmiştir.

Çalışmanın üçüncü başlığı olan "Veri ve Yöntem” bölümünde analizlerde kullanılacak ana ve alt kriterler açıklanmaya çalışılmış, AB üye ülkelerinin küresel cinsiyet ayrımı bakımından sıralaması yapılırken kullanılacak olan yöntemler anlatılmıştır. Dördüncü bölümde ise uygulanan analizlerin adımları kısaca paylaşılmış, bulgulara yer verilmiştir. Sonuç bölümünde bulgular üzerinden çıkarımlar yapılmıştır.

\section{Literatür İncelemesi}

Küresel Cinsiyet Ayrımı Endeksi'nin (GGGI) verilerini kullanarak ülkeleri cinsiyet eşitliği açısından karşılaştırmayı amaçlayan çalışmalardan bazıları aşağıda özetlenmiştir. 
Bağdatlı Kalkan (2018), çalışmasında 2017 yılına ait GGGI verilerine göre Dünya Bankası'nın kişi başı gayri safi milli gelire (GSMG) göre üst-orta olarak sınıflandırdığı 40 ülkeyi cinsiyet eşitliği açısından sıralamayı amaçlamıştır. Sıralama için gri ilişkisel analiz kullanıp elde ettiği sıralamaları ile GGGI sıralamaları arasında Spearman Korelasyon analizi gerçekleştirip \%76 düzeyinde pozitif ilişki tespit etmiştir.

Koca (2018), insani gelişmişlik düzeyi düşük olan 23 ülkenin cinsiyet eşitliğini işgücüne katılım, ekonomik liderlik, politik liderlik, eğitim, sağlık, mezuniyet derecesine göre sektörel oranlar boyutları açısından değerlendirmiştir.

Durgun ve Oğuz Gök (2017), BRICS ve G7 grubu ülkelerin toplumsal cinsiyet eşitliği açısından karşılaştırarak değerlendirmişlerdir. 2008-2015 GGGI verileri ile Birleşmiş Milletler (BM) İnsani Gelişmişlik Endeksi (İGE) verilerini kullandıkları çalışmada seçilen ülkelerin İGE verileri ile benzer bir sıralama olduğunu fakat GGGI verilerine göre sıralamada fark edilebilir bir değişiklik olduğunu açıklamışlardır.

Macáková (2016), çalışmasında Macaristan, Polonya, Çek Cumhuriyeti ve Slovakya için GGGI verilerini karşılaştırmayı ve 2006-2015 döneminde Çek Cumhuriyeti'nin bu dört ülke arasındaki sıralamasını belirlemeyi amaçlamıştir.

Kharchenko'nun (2016), Ermenistan, Azerbaycan, Gürcistan, Moldova, Ukrayna ve Rusya'nın GGGI verilerini inceleyerek karşılaştırma yapmıştır. Bu ülkelerin GGGI açısından güçlü ve zayıf yönlerini açıklayan çalışmada en eşitlikçi ülke ve en az eşitlik deneyimi sunan ülkeleri değerlendirmiştir.

Gençoğlu ve Kuşkaya (2016), Orta Asya ve Avrupa'dan 38 ülkenin GGGI verilerini kullanıp, Ward yöntemi ile kümeleme analizi yaparak, bu ülkelerin kişi başına düşen milli gelir düzeyi benzer olan ülkelerin cinsiyet ayrımı açısından aynı kümede yer aldıklarını belirtmişlerdir.

ARAS, COPRAS ve GİA yöntemlerini kullanarak gerçekleştirilen çalışmaların bazıları aşağıda özetlenmiştir.

Kose, Vural ve Canbulut (2020), Türkiye' nin en yaşanabilir şehrini belirlemek amacıyla kişilere anket uygulayarak değerlendirmede kullanılacak kriterleri belirlemiş, bu kriterlere AHP yöntemi uygulayarak kriterlerin ağırlıklarını hesaplamış, bu kriterlere ilişkin olarak GİA yöntemiyle 6 şehir arasından sıralama yaparak en yaşanabilir ilin İzmir olduğunu açıklamışlardır. 
Škrinjaric (2020), hisse senetlerinin sıralamasından yararlanarak GİA yöntemiyle dinamik portföy değerlendirmesi gerçekleştirmiştir. Zagreb Borsası'ndan gıda, inşaat, turizm, sanayi ve ulaşım sektörleri için toplanan günlük verilere GİA yöntemini uygulayarak yatırımcının tercihlerine göre şekillenebilen bir portföy seçim alternatifi oluşturmuştur.

Türe (2019), OECD ülkelerinin 2000-2014 dönemi için refah skorlarının değerlendirmesini yapmak üzere entropi temelli GİA uygulaması gerçekleştirmiş̧ir. Uygulamada kriterlerin eşit öneme sahip olduğu ve kriter ağırlıklarının entropi yöntemi ile belirlediği iki modeli deneyerek Türkiye'nin değerlendirmesini diğer ülkeler ile karşılaştırmıştır.

Özbek ve Demirkol (2019), AB üye ülkeleri ve Türkiye'nin 2016 ekonomik gösterge değerlerini kullanarak bir ekonomik performans ölçüm modeli geliştirmişlerdir. Toplam 8 göstergenin kullanıldığı çalışmada göstergelerin ağırlıklarını analitik hiyerarşik süreç (AHS) yöntemiyle hesaplamış, sonrasinda ARAS, COPRAS ve GİA yöntemlerini kullanarak bu ülkeleri ekonomik performans açısından değerlendirmişlerdir.

Roy vd., (2019), otel alternatifleri arasından belirlenen kriterler vasitasiyla otel seçimi yapmayı amaçlamışlardır. Çalışmada WIRN yöntemi ile kriter ağırlıklarını belirlemiş, COPRAS yöntemi ile otel tercihlerini sıralamış, ardından modelin geçerliliğini belirlemek üzere duyarlılık analizi gerçekleştirmişlerdir.

Emovon ve Mgbemena (2018), optimum planlı değiştirme zaman aralığı probleminin çözümünde TOPSIS, ARAS ve WASPAS yöntemlerini karşılaştırarak, uygulama kolaylığı açısından ARAS ve WASPAS yönteminin TOPSIS yöntemine göre benzer sonuçlar ürettikleri ve bu yöntemlerin uygulama açısından kolay olması nedeniyle tercih edilebileceğini belirtmişlerdir.

Šoltés ve Nováková (2016), Vişegrad Grubu'nu (Polonya, Çek Cumhuriyeti, Macaristan ve Slovakya) yaşam kalitesinin fiziksel boyutu açısından değerlendirmeyi amaçlamışlar, 2005-2013 dönemi için ARAS yöntemini kullanarak gerçekleştirdikleri sıralama sonuçlarına ilişkin olarak bu ülkelere yaşam kalitesinin geliştirilmesi adına önerilerde bulunmuşlardır.

Pitchipoo vd. (2014), Hindistan'da bir toplu taşıma şirketinin ağır vasıtalarında kör noktaların azaltılması için dikiz aynası tasarımında kullanılan parametrelerin optimizasyonunu sağlamaya çalışmışlardır. Çalışmada kriterlerin ağırlıklarını AHP, FARE ve Entropi yöntemi ile hesaplayarak COPRAS yöntemi ile alternatifleri değerlendirmişlerdir. 


\section{Veri ve Yöntem}

Çalışmanın verileri Dünya Ekonomik Forumu (WEF- World Economic Forum) tarafından yıllık veriler ile hazırlanan Küresel Cinsiyet Ayrımı Raporu'ndan (The Global Gender Gap Report) elde edilmiştir. İlgili raporun 2017, 2018 ve 2020 sayılarından ülkelerin puan kartlarında yer alan verilerden yararlanılarak bir veri seti oluşturulmuştur. 2019 yılında rapor yayınlanmadığından dolayı 2020 raporu kullanılmıştır. Kriterler "Ekonomik katılım ve fırsat", "Eğitim durumu", “Sağlık ve Sağkalım” ve "Siyasi güçlendirme" olarak 4 ana kriter altında yer almıştır. Rapora ilişkin olarak ana kriterlerin tamamının ağırlıkları eşit olmakla birlikte alt kriterlerin ana kriter içerisindeki ağırlıkları değişmekte, kriterlerin ağırlıkları WEF raporunda yer verildiği gibi tüm yıllar için aynı değerleri almaktadır. WEF raporunda kriter değerleri, ilgili kriter için kadın/erkek oranı ile elde edilmiştir. Tablo 1'de çalışmada kullanılan kriterler, kriterlerin ağırlıkları ve yönleri gösterilmektedir (WEF, 2017; WEF, 2018; WEF, 2020).

Tablo 1. Çalışmanın kriterleri

\begin{tabular}{llll}
\hline Kriter & Kriter Kodu & Ağırlığı & Yönü \\
\hline Ekonomik Katılım ve Fırsat Ana Kriteri & EK & $\mathbf{1 . 0 0 0}$ & \\
İşücüne katılım kriteri & EK1 & 0.199 & Fayda \\
Ücret eşitliği kriteri & EK2 & 0.310 & Fayda \\
Tahmini kazanç kriteri & EK3 & 0.221 & Fayda \\
Milletvekili, yönetici ve üst düzey memurlar oranı kriteri & EK4 & 0.149 & Fayda \\
Profesyoneller ve teknik çalışanlar oranı kriteri & EK5 & 0.121 & Fayda \\
Eğitim Durumu Ana Kriteri & ED & $\mathbf{1 . 0 0 0}$ & \\
Okuma-yazma oranı kriteri & ED1 & 0.191 & Fayda \\
İköğretime kayıt kriteri & ED2 & 0.459 & Fayda \\
Ortaöğretime kayıt kriteri & ED3 & 0.230 & Fayda \\
Yükseköğretime kayıt kriteri & ED4 & 0.121 & Fayda \\
Sağlık ve Sağkalım Ana Kriteri & SS & $\mathbf{1 . 0 0 0}$ & \\
Doğumda cinsiyet oranı kriteri & SS1 & 0.693 & Fayda \\
Sağlıklı yaşam beklentisi kriteri & SS2 & 0.307 & Fayda \\
Siyasi Güçlendirme Ana Kriteri & SG & $\mathbf{1 . 0 0 0}$ & \\
Parlamentodaki kadınların oranı kriteri & SG1 & 0.310 & Fayda \\
Bakanlık pozisyonundaki kadınların oranı kriteri & SG2 & 0.247 & Fayda \\
Kadın devlet başkanlarının yönetimdeki oranı kriteri & SG3 & 0.443 & Fayda \\
\hline
\end{tabular}

Kaynak: WEF, 2017; WEF, 2018; WEF, 2020.

Raporlarda bazı ülkelerin kriterler için değerlerinde eksiklikler bulunmaktadır. Bu eksiklikler diğer kriterlerin değerleri ve ağırlıkları ile yıllık toplam skor hesaplaması ile tamamlanmıştır. 
Çalışma için Avrupa Birliği (AB) üye ülkeleri verileri kullanılmıştır. Üye ülkeler 2017 ve 2018 yıllarında 28 ülke iken 2020 yılında İngiltere'nin AB'den ayrılması ile 27 ülke olarak kabul edilmiştir. Çalışmaya dahil edilen ülkeler tablo 2'de gösterilmiştir (European Union, 30.06.2020).

Tablo 2. Çalışmaya dahil edilen ülkeler

\begin{tabular}{llllllll}
\hline Ülke & Kodu & Ülke & Kodu & Ülke & Kodu & Ülke & Kodu \\
\hline Avusturya & AUT & Estonya & EST & İtalya & ITA & Portekiz & PRT \\
Belçika & BEL & Finlandiya & FIN & Litvanya & LTU & Romanya & ROU \\
Bulgaristan & BGR & Fransa & FRA & Letonya & LVA & Slovakya & SVK \\
Hırvatistan & HRV & Almanya & DEU & Lüksemburg & LUX & Slovenya & SVN \\
Gün. Kıbrıs & CYP & Yunanistan & GRC & Malta & MLT & İspanya & ESP \\
Çekya & CZE & Macaristan & HUN & Hollanda & NLD & İsveç & SWE \\
Danimarka & DNK & İrlanda & IRL & Polonya & POL & İngiltere* & UK \\
\hline
\end{tabular}

Kaynak: EU, 2020. * İngiltere analizlere yalnızca 2017 ve 2018 yıllarında dahil edilmiştir.

Çalışmada $\mathrm{AB}$ üye ülkelerinin cinsiyet eşitliği sıralamalarını değerlendirmek için Gri İlişkisel Analiz, ARAS ve COPRAS yöntemleri kullanılmıştır. Takip eden bölümlerde yöntemler açıklanmıştır.

\section{Gri Sistem Teorisi ve Gri İlişkisel Analiz}

Gri sistem teorisi (GST), Deng (1982) tarafından literatüre kazandırılan bir teoridir. Gri sistem, bilinen ve bilinmeyen özellikler içeren sistemleri niteleyen bir kavramdır. Bu özelliği ile doğa bilimleri ve sosyal bilimler arasındaki boşluğu kapatmak için oldukça uygun görülmekte ve disiplinler arası bir teori olduğu belirtilmektedir. Hukuk, jeoloji, yönetim, malzeme bilimi, tarım, ekonomi gri sistem teorisinin uygulama alanlarından bazılarıdır.

(Deng, 1989, s.1).

GST'ye göre gerçek hayatta karşılaşılan problemlerin bilinen yanları beyaz , bilinmeyen yanları ise siyah olarak nitelendirilir ve her ikisinin de aynı sistemde bulunması gri sistemi ortaya çkarır. Sistemdeki bilinmeyenler (eksiklikler) dört durumdan en az biri olarak ortaya çkar. Bu dört durum sistem parametreleri hakkında, sistem yapıları hakkında, sistem sınırları hakkında ve sistemin davranışları hakkında bilgi eksikliğidir (Liu ve Lin, 2006, s. 4). GST'nin odak noktası, eksik bilgi içeren belirsizlik problemlerinin küçük örneklemler aracilığıyla çözümlenmesidir (Liu, Forrest ve Yang, 2013). 
Gri ilişkisel analiz (GİA), GST'ye dayanan, çoklu faktörler ve değişkenler arasındaki ilişkileri çözümlemek için uygulanabilen bir karar verme yöntemidir (Wang, Zhu ve Wang, 2016, s. 4). Yöntemin başlıca gereksinimi, tüm alternatiflerin kriter değerlerinin kıyaslanabilir olmasıdır. Gri ilişkisel derecelendirme olarak da anılan bu aşamada birer dizi olarak kabul edilen alternatifler, belirlenen referans dizi ile aralarındaki geometrik benzerlik kullanılarak gri ilişkisel dereceler hesaplanır. En yüksek gri ilişkisel dereceli diziler seçilerek amaca ulaşılır (Başdeğirmen ve Iş̧ldak, 2018, s. 565; Yıldırım, 2015.a, s. 231). Şekil 1'de GİA'nın uygulama adımları gösterilmiştir (Ayçin, 2019, s. 134).

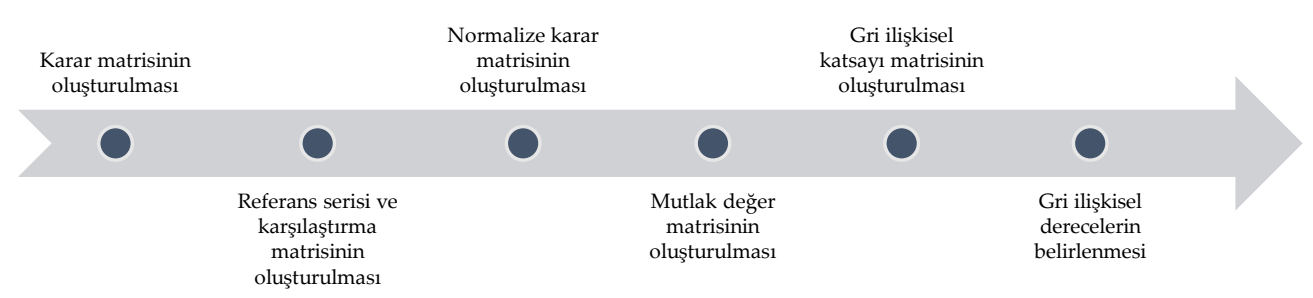

Şekil 1. GİA uygulama adımları (Ayçin'den (2019) yararlanılarak hazırlanmıştır)

GİA'nın uygulamasına ilişkin adımlar aşağıdaki gibidir (Ayçin, 2019, s. 134-138):

İlk adımda uygulamaya ait karar matrisi $n$ kriter ve m adet alternatife göre oluşturulur. Matrisin matematiksel ifadesine formül (1)'de yer verilmiştir. $x_{i}^{\prime} l e r$ alternatifleri, $x_{i}(j)$ 'ler ise $i$. alternatifin $j$. kriter için aldığı değeri ifade eder.

$$
x_{i}=\left(x_{i}(j), \ldots, x_{i}(n)\right) i=1,2, \ldots, m \text { ve } j=1,2, \ldots, n
$$

Oluşan matris formül (2)'deki gibi görünecektir.

$$
\mathbf{X}=\left[\begin{array}{ccc}
\mathbf{x}_{\mathbf{1}}(\mathbf{1}) & \cdots & \mathbf{x}_{\mathbf{1}}(\mathbf{n}) \\
\vdots & \ddots & \vdots \\
\mathbf{x}_{\mathbf{m}}(\mathbf{1}) & \cdots & \mathbf{x}_{\mathbf{m}}(\mathbf{n})
\end{array}\right]
$$

Sonraki adım olan referans serisinin matematiksel ifadesi formül (3)'te gösterilmiştir. Gösterimdeki x0(j), j. kriterin normalize değerleri içerisindeki 
en iyi değerini ifade etmektedir. Normalize değerlere bir sonraki adımda ulaşılacaktır. Referans seti, karar matrisinin ilk satırına yerleştirilir ve karşılaştırma matrisine dönüştürülür.

$$
x_{0}=\left(x_{0}(j)\right) j=1,2, \ldots, n
$$

Normalize karar matrisi oluşturulurken kriterin yönü dikkate alınır. Kriterler fayda, maliyet ve optimal durum olarak üç farklı yönde olabilirler. Fayda yönlü kriterler maksimize edilmeye çalışılan kriterler iken maliyet yönlü kriterler minimize edilmeye çalışılan kriterlerdir. Optimal durum değerlendiren kriterler ise belirlenen bir optimal duruma göre değer almak zorunda olan kriterlerdir.

Fayda yönlü kriterler için formül (4)'te, maliyet yönlü kriterler için formül (5)'te ve optimal durumlu kriterler için formül (6)' da gösterildiği gibi normalizasyon yapılmaktadır.

$$
\mathbf{x}_{\mathbf{i}}^{*}=\frac{\mathrm{x}_{\mathrm{i}}(\mathrm{j})-\min _{\mathbf{i}} \mathrm{x}_{\mathrm{i}}(\mathrm{j})}{\max _{\mathbf{j}} \mathrm{x}_{\mathrm{i}}(\mathrm{j})-\min _{\mathrm{j}} \mathrm{x}_{\mathrm{i}}(\mathrm{j})}
$$

$$
\mathbf{x}_{\mathbf{i}}^{*}=\frac{\max _{\mathbf{j}} \mathrm{x}_{\mathrm{i}}(\mathrm{j})-\mathrm{x}_{\mathbf{i}}(\mathrm{j})}{\max _{\mathbf{j}} \mathrm{x}_{\mathbf{i}}(\mathrm{j})-\min _{\mathbf{j}} \mathrm{x}_{\mathrm{i}}(\mathrm{j})}
$$

$$
\mathbf{x}_{\mathbf{i}}^{*}=\frac{\left|\mathrm{x}_{\mathrm{i}}(\mathrm{j})-\mathrm{x}_{0 \mathbf{b}}(\mathrm{j})\right|}{\max _{\mathbf{j}} \mathbf{x}_{\mathbf{i}}(\mathrm{j})-\mathbf{x}_{0 \mathbf{b}}(\mathbf{j})}
$$

Bu aşamalardan sonra karar matrisi, formül (7)'de görüldüğü gibi normalize karar matrisine dönüştürülmüş olur.

$$
\mathbf{X}^{*}=\left[\begin{array}{ccc}
\mathbf{X}_{\mathbf{1}}^{*}(\mathbf{1}) & \cdots & \mathbf{x}_{\mathbf{1}}^{*}(\mathbf{n}) \\
\vdots & \ddots & \vdots \\
\mathbf{x}_{\mathbf{m}}^{*}(\mathbf{1}) & \cdots & \mathbf{x}_{\mathbf{m}}^{*}(\mathbf{n})
\end{array}\right]
$$

Bir sonraki aşama olan mutlak değer matrisine ulaşmak için uygulanması gereken formül (8)'de, ulaşılan mutlak değer matrisi formül (9)'da görüldüğü gibidir.

$$
\begin{aligned}
\Delta_{\mathbf{0}} & =\left|\mathbf{x}_{\mathbf{0}}^{*}(\mathbf{j})-\mathbf{x}_{\mathbf{i}}^{*}(\mathbf{j})\right| \\
\mathbf{X}^{*} & =\left[\begin{array}{ccc}
\Delta_{\mathbf{0 1}}(\mathbf{1}) & \cdots & \Delta_{\mathbf{0 1}}(\mathbf{n}) \\
\vdots & \ddots & \vdots \\
\Delta_{\mathbf{0 m}}(\mathbf{1}) & \cdots & \Delta_{\mathbf{0 m}}(\mathbf{n})
\end{array}\right]
\end{aligned}
$$


Gri ilişkisel katsayı matrisini oluşturmak üzere formül (10) kullanılır. Formül (10)'da görülen $\zeta$ ayırıcı katsayıyı ifade etmektedir. Ayırıc katsayı 0-1 aralığında değer alan zıtlık parametresi olarak da anılır. Değeri 1'e yaklaştıkça ayırıcı özellik artacak, 0 'a doğru yaklaştıkça zıtlık azalacaktır.

$$
\begin{aligned}
& \gamma_{0 \mathbf{i}}(\mathbf{j})=\frac{\Delta_{\min }+\zeta \Delta_{\max }}{\Delta_{0 \mathbf{i}}(\mathbf{j})+\zeta \Delta_{\max }}, \\
& \Delta_{\max }=\max _{\mathbf{i}} \max _{\mathbf{j}} \Delta_{\mathbf{0}}(\mathbf{j}) \text { ve } \Delta_{\min }=\min _{\mathbf{i}} \min _{\mathbf{j}} \Delta_{\mathbf{0}}(\mathbf{j})
\end{aligned}
$$

Uygulamanın son adımı olan gri ilişkisel derecelerin $\left(\boldsymbol{\Gamma}_{\mathbf{0} \mathbf{i}}\right)$ belirlenmesi için hesaplamaya başlanmadan önce kriterlerin önem düzeylerinin eşit olup olmadığına dikkat edilmelidir. Eğer kriterler eşit önem derecesindeler ise (11), farklı önem derecelerine sahiplerse ağırlıkların (wi(j)) eklendiği formül (12) kullanılmalıdır.

$$
\begin{aligned}
\Gamma_{0 i} & =\frac{1}{n} \sum_{j=1}^{n} \Upsilon_{0 i}(j) \\
\Gamma_{0 i} & =\sum_{j=1}^{n}\left[w_{i}(j) \cdot \Upsilon_{0 i}(j)\right]
\end{aligned}
$$

Gri ilişkisel derecelerin belirlenmesinin ardından sıralamaları yapılmalıdır. Referans seriye geometrik benzerlik açısından büyükten küçüğe doğru sıralanan alternatifler arasından en büyük gri ilişkisel dereceye sahip olan alternatif problem için en uygun çözüm olarak belirlenir (Yıldırım, 2015.a, s. 232-236; Ayçin, 2019, s. 134-138).

\section{ARAS}

ARAS (Additive Ratio Assessment) yöntemi Zavadskas ve Turskis (2010) tarafından yapılan bir çalışmada kullanılmıştır. Bilinen birçok ÇKKV yönteminde alternatiflerin ideal pozitif ve ideal negatif çözüme olan mesafeleri dikkate alınarak karar verilirken ARAS için bu durum değişmektedir. ARAS'a göre bir ÇKKV problemindeki alternatifin fayda fonksiyonu değeri, kriterlerin değerlerinin ve ağırlıklarının nispi etkisi ile doğru orantılıdır. Problemin çözüm alternatiflerinin fayda fonksiyonu değerleri araştırmacı tarafından eklenen bir optimal alternatifin fayda fonksiyonu değeri ile karşılaştırılarak sonuca ulaşılır (Zavadskas ve Turskis, s. 165, 2010; Yıldırım, 2015.b). ARAS yönteminin uygulama adımları Şekil 2'de gösterilmektedir. 


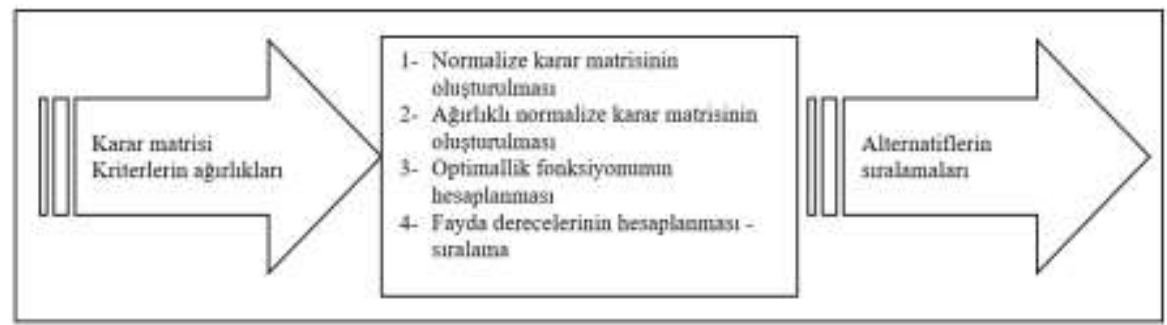

Şekil 2. ARAS yöntemi girdileri, uygulama adımlan ve çıktılan (Kaynak: Alinezhad ve Khalili, 2019, s. 71)

Karar matrisi ve kriter ağırlıklarının girdi olarak verildiği süreçte ilk uygulama adımı normalize karar matrislerini oluşturmaktır. Bu adımda yine kriterlerin yönleri önemlidir. Fayda yönlü kriterler için normalleştirme formül (13), maliyet yönlü kriterler için ise formül (14)'te görüldüğü gibi yapılmaktadır. Matematiksel gösterimlerde $\mathrm{m}$ alternatif sayısını, $n$ kriter sayısını, $\mathbf{x}_{\mathrm{ij}} i$. alternatifinin $j$. kriterinin değerini, $\mathbf{x}_{\mathbf{0}} \mathbf{j}$ kriterinin optimal değerini, $\mathbf{w}_{\mathbf{j}} j$ kriterinin ağırlığını, $\overline{\mathbf{x}}_{\mathbf{i j}} i$ alternatifinin $j$. kriterinin normalize değerini, $\overline{\mathbf{X}}$ normalize karar matrisini, $\hat{\mathbf{x}}_{\mathbf{i j}} i$. alternatifinin $j$. kriteri için ağırlıklı normalize değerini ifade etmekte, böylece ARAS yöntemine ilişkin formüller aşağıda gösterilmektedir (Zavadskas ve Turskis, 2010, s. 163-165):

$$
\begin{aligned}
\overline{\mathbf{x}}_{i j} & =\frac{\mathrm{x}_{i j}}{\sum_{\mathrm{i}=0}^{\mathrm{m}} \mathrm{x}_{\mathrm{ij}}} \\
\mathbf{x}_{\mathrm{ij}} & =\frac{1}{\mathrm{x}_{\mathrm{ij}}} ; \quad \overline{\mathbf{x}}_{\mathrm{ij}}=\frac{\mathrm{x}_{\mathrm{ij}}}{\sum_{\mathrm{i}=0}^{\mathrm{m}} \mathrm{x}_{\mathrm{ij}}}
\end{aligned}
$$

Ağırlıklı normalize karar matrisine ulaşmak için formül (15)'te görüldüğü gibi normalize değerler, kriter ağırlıkları ile çarpılır.

$$
\hat{\mathbf{x}}_{\mathbf{i j}}=\overline{\mathbf{x}}_{\mathrm{ij}} \mathbf{w}_{\mathbf{j}}
$$

Optimallik fonksiyonu $\left(\mathrm{S}_{\mathrm{i}}\right)$ her alternatif için formül (16)'daki gibi hesaplanir.

$$
\mathbf{S}_{\mathbf{i}}=\sum_{\mathbf{j}=\mathbf{1}}^{\mathbf{n}} \hat{\mathbf{x}}_{\mathbf{i j}}
$$

Fayda derecesi $\left(\mathrm{K}_{\mathrm{i}}\right)$, alternatiflerin optimallik fonksiyonu değerleri $\left(\mathrm{S}_{\mathrm{i}}\right)$ ve en iyi alternatifin optimallik fonksiyon değeri ( $\mathrm{S}_{0}$ ) formül (17) kullanılarak hesaplanır. Sonrasında [0,1] aralığında olan fayda derecelerine göre alternatifler 
sıralanarak ARAS yöntemi sonlandırılır (Zavadskas ve Turskis, 2010, s. 163165; Alinezhad ve Khalili, 2019, s. 68-69; Ayçin, 2019, s. 52-55).

$$
\mathbf{K}_{\mathbf{i}}=\frac{\mathbf{s}_{\mathbf{i}}}{\mathbf{s}_{\mathbf{0}}}
$$

\section{COPRAS}

COPRAS (COmplex PRoportional ASsessment) Zavadskas, Kaklauskas, ve Sarka (1994) tarafından literatüre kazandırılan bir ÇKKV yöntemidir. Literatürde yatırım değerlendirme, proje seçimi, malzeme seçimi, karar destek sistemi geliştirilmesi gibi birçok seçim probleminde kullanılmış olan bu yöntem, hem nitel hem de nicel kriterler ile çalışabilme özelliğine sahiptir (Alinezhad ve Khalili, 2019, s. 87; Ayçin, 2019, s. 64).

COPRAS'ın uygulama adımları birçok ÇKKV yönteminde olduğu gibi karar matrisinin formül (18)'de gösterildiği gibi normalize edilmesi ve formül (19)'da görülen normalize karar matrisinin formül (20)' deki gibi ağırlıklandırılması ile başlar. Diğer yöntemlerden farklı olarak bir sonraki adımda ağırlıklandırılmış normalize karar matrisindeki kriter değerleri toplanır. $\mathrm{Bu}$ adımda fayda yönlü kriterler için formül (21) ve maliyet yönlü kriterler için formül (22) kullanılarak işlem yapılır. Ardından alternatiflerin göreli önem düzeyleri formül (23) ile hesaplanır ve en yüksek önem düzeyine sahip alternatif ÇKKV problemi için en uygun çözüm olan alternatif olarak değerlendirilir. Son olarak alternatiflerin performans indeksleri formül (24)'te görüldüğü gibi göreli önem düzeyleri yardımıyla yüzde cinsinden hesaplanır ve sıralanır. Sonuçta alternatiflerin ÇKKV problemi için uygunluğuna göre sıralı hali elde edilir, COPRAS yöntemine ilişkin formüller aşağıda verilmiştir (Alinezhad ve Khalili, 2019, s. 88-89; Aksoy, Ömürbek ve Karaatlı, 2015; Zavadskas, Kaklauskas, Peldschus ve Turskis, 2007, s. 199-200):

$$
\begin{aligned}
x_{i j}^{*} & =\frac{x_{i j}}{\sum_{i=1}^{m} x_{i j}} \\
D^{\prime} & =\left[\begin{array}{ccc}
d_{11} & \cdots & d_{1 n} \\
\vdots & \ddots & \vdots \\
d_{m 1} & \cdots & d_{m n}
\end{array}\right] \\
d_{i j} & =x_{i j}^{*} \cdot w_{j} \\
S_{+i} & =\sum_{j=1}^{k} d_{+i j} \\
S_{-i} & =\sum_{j=k+1}^{n} d_{-i j}
\end{aligned}
$$




$$
\begin{aligned}
& \mathcal{Q}_{i}=S_{+i}+\frac{S_{-\min } \sum_{i=1}^{m} S_{-i}}{S_{-i} \cdot \sum_{i=1}^{m} \frac{S_{\min }}{S_{-i}}} \\
& \boldsymbol{P}_{i}=\frac{Q_{i}}{Q_{\max }} \cdot \mathbf{1 0 0}
\end{aligned}
$$

\section{Analiz ve Bulgular}

Bu çalışmada $A B$ üye ülkelerinin cinsiyet eşitliği sıralamalarına ulaşmak için kullanılan Gri İlişkisel Analiz, ARAS ve COPRAS yöntemleri kullanılmıştır. Bu bölümde yöntemlerin uygulama adımları açıklanacaktır. Verideki kriterler ile ilgili bilgiler "Veri ve Yöntem" başlıklı bölümde sunulmuştur.

Kullanılan yöntemlerin ortak noktası olan karar matrisi oluşturulması adımı için 2017 yılının örnek karar matrisi Tablo 3'te verilmiştir.

\begin{tabular}{|c|c|c|c|c|c|c|c|c|c|c|c|c|c|c|}
\hline \multirow{2}{*}{$\begin{array}{l}\text { Krit. } \\
\text { Ülke }\end{array}$} & \multicolumn{5}{|l|}{ EK } & \multicolumn{4}{|l|}{ ED } & \multicolumn{2}{|l|}{ SS } & \multicolumn{3}{|l|}{ SG } \\
\hline & 1 & 2 & 3 & 4 & 5 & 1 & 2 & 3 & 4 & 1 & 2 & 1 & 2 & 3 \\
\hline AUT & .88 & .59 & .52 & .46 & .93 & 1 & .99 & .97 & 1 & .94 & 1.04 & .44 & .30 & .011 \\
\hline BEL & .87 & .66 & .64 & .48 & 1 & 1 & 1 & 1 & 1 & .94 & 1.04 & .61 & .30 & 0 \\
\hline BGR & .89 & .56 & .65 & .61 & 1 & .99 & .99 & .97 & 1 & .94 & 1.06 & .31 & 1 & .00 \\
\hline HRV & .86 & .55 & .72 & .42 & 1 & .99 & .99 & 1 & 1 & .94 & 1.06 & .22 & .25 & .10 \\
\hline CYP & .86 & .60 & .66 & .35 & 1 & .98 & 1 & 1 & 1 & .93 & 1.03 & .21 & .10 & 0 \\
\hline CZE & .81 & .58 & .59 & .34 & .95 & 1 & .99 & 1 & 1 & .94 & 1.06 & .25 & .21 & 0 \\
\hline DNK & .92 & .69 & .67 & .38 & 1 & 1 & 1 & 1 & 1 & .94 & 1.03 & .59 & .75 & .08 \\
\hline EST & .90 & .65 & .61 & .56 & 1 & 1 & 1 & 1 & 1 & .94 & 1.06 & .36 & .40 & .01 \\
\hline FIN & .96 & .79 & .71 & .51 & 1 & 1 & 1 & 1 & 1 & .94 & 1.05 & .72 & .62 & .31 \\
\hline FRA & .89 & .47 & .73 & .49 & 1 & 1 & 1 & 1 & 1 & .94 & 1.05 & .63 & 1 & .01 \\
\hline DEU & .88 & .67 & .68 & .41 & 1 & 1 & .99 & .95 & .95 & .94 & 1.04 & .58 & .50 & .31 \\
\hline GRC & .77 & .63 & .65 & .34 & 1 & .98 & .99 & .98 & .99 & .93 & 1.04 & .22 & .26 & .001 \\
\hline HUN & .82 & .49 & .63 & .64 & 1 & 1 & .98 & 1 & 1 & .94 & 1.06 & .11 & 0 & 0 \\
\hline IRL & .80 & .69 & .58 & .55 & 1 & 1 & 1 & 1 & 1 & .94 & 1.03 & .28 & .36 & .71 \\
\hline ITA & .73 & .48 & .51 & .38 & .83 & .99 & .99 & .99 & 1 & .94 & 1.02 & .44 & .38 & 0 \\
\hline LVA & .92 & .66 & .70 & .89 & 1 & 1 & 1 & 1 & 1 & .94 & 1.06 & .19 & .30 & .25 \\
\hline LTU & .93 & .59 & .72 & .65 & 1 & 1 & 1 & 1 & 1 & .94 & 1.06 & .27 & .27 & .20 \\
\hline LUX & .83 & .71 & .62 & .21 & .90 & 1 & 1 & 1 & 1 & .94 & 1.03 & .39 & .25 & 0 \\
\hline MLT & .63 & .69 & .49 & .40 & .81 & 1 & 1 & 1 & 1 & .94 & 1.03 & .13 & .06 & .19 \\
\hline NLD & .87 & .67 & .48 & .34 & .95 & 1 & 1 & 1 & 1 & .94 & 1.02 & .56 & .60 & 0 \\
\hline POL & .82 & .55 & .63 & .70 & 1 & 1 & 1 & 1 & 1 & .94 & 1.06 & .39 & .29 & .08 \\
\hline PRT & .91 & .59 & .72 & .55 & 1 & .96 & .99 & 1 & 1 & .94 & 1.05 & .53 & .28 & .00 \\
\hline ROU & .77 & .63 & .69 & .50 & 1 & .99 & .99 & 1 & 1 & .94 & 1.06 & .26 & .31 & 0 \\
\hline SVK & .81 & .53 & .60 & .53 & 1 & 1 & 1 & 1 & 1 & .94 & 1.06 & .25 & .16 & .03 \\
\hline SVN & .90 & .70 & .80 & .69 & 1 & 1 & 1 & 1 & 1 & .94 & 1.06 & .57 & 1. & .03 \\
\hline ESP & .86 & .50 & .63 & .45 & .99 & .98 & 1 & 1 & 1 & .94 & 1.04 & .64 & .62 & 0 \\
\hline SWE & .94 & .73 & .78 & .64 & 1 & 1 & 1 & .99 & 1 & .94 & 1.02 & .77 & 1 & 0 \\
\hline UK & .87 & .67 & .55 & .56 & .97 & 1 & .99 & 1 & 1 & .94 & 1.03 & .47 & .44 & .33 \\
\hline
\end{tabular}

Tablo 3. 2017 yılı GIA, ARAS ve COPRAS uygulamaları için karar matrisi 


\section{GíA Uygulaması}

GİA uygulamasında formül (3) ile referans serisi oluşturma, formül (4) ile normalize matris oluşturma, formül (8) ile mutlak değer matrisi oluşturma ve formül (10) ile gri ilişkisel katsayı matrisi oluşturma adımlarının uygulanmasından sonra erişilen gri ilişkisel katsayı matrisi tablo 4'te gösterilmektedir.

Tablo 4. 2017 yılı GİA uygulaması gri ilişkisel katsayı matrisi

\begin{tabular}{|c|c|c|c|c|c|c|c|c|c|c|c|c|c|c|}
\hline Krit. & EK & & & & & ED & & & & SS & & SG & & \\
\hline Ülke & 1 & 2 & 3 & 4 & 5 & 1 & 2 & 3 & 4 & 1 & 2 & 1 & 2 & 3 \\
\hline AUT & .67 & .44 & .37 & .44 & .85 & 1 & .97 & .93 & 1 & 1 & .96 & .49 & .41 & .33 \\
\hline BEL & .63 & .55 & .51 & .45 & 1 & 1 & 1 & 1 & 1 & 1 & .97 & .67 & .41 & .33 \\
\hline BGR & .69 & .41 & .51 & .54 & 1 & .98 & .98 & .93 & 1 & .99 & 1 & .41 & 1 & .33 \\
\hline HRV & .62 & .39 & .68 & .42 & 1 & .97 & .98 & 1 & 1 & 1 & 1 & .37 & .40 & .37 \\
\hline CYP & .62 & .45 & .54 & .38 & 1 & .97 & 1 & 1 & 1 & .97 & .94 & .37 & .35 & .33 \\
\hline CZE & .52 & .43 & .44 & .37 & .90 & 1 & .97 & 1 & 1 & 1 & 1 & .38 & .38 & .33 \\
\hline DNK & .81 & .62 & .55 & .40 & 1 & 1 & 1 & 1 & 1 & 1 & .94 & .65 & .66 & .36 \\
\hline EST & .71 & .54 & .47 & .50 & 1 & 1 & 1 & 1 & 1 & .99 & 1 & .44 & .45 & .33 \\
\hline FIN & 1 & 1 & .63 & .47 & 1 & 1 & 1 & 1 & 1 & 1 & .99 & .87 & .57 & .47 \\
\hline FRA & .70 & .33 & .71 & .45 & 1 & 1 & 1 & 1 & 1 & 1 & .98 & .71 & 1 & .33 \\
\hline DEU & .67 & .58 & .57 & .41 & 1 & 1 & .97 & .88 & .90 & 1 & .96 & .64 & .50 & .47 \\
\hline GRC & .46 & .50 & .52 & .38 & 1 & .95 & .98 & .97 & .99 & .98 & .97 & .37 & .40 & .33 \\
\hline HUN & .54 & .34 & .48 & .57 & 1 & 1 & .96 & 1 & 1 & .99 & 1 & .33 & .33 & .33 \\
\hline IRL & .51 & .62 & .42 & .50 & 1 & 1 & 1 & 1 & 1 & .99 & .94 & .40 & .44 & 1 \\
\hline ITA & .41 & .34 & .36 & .39 & .70 & .98 & .98 & .99 & 1 & .99 & .92 & .50 & .44 & .33 \\
\hline LVA & .79 & .54 & .61 & 1 & 1 & 1 & 1 & 1 & 1 & 1 & 1 & .36 & .41 & .43 \\
\hline LTU & .86 & .44 & .66 & .58 & 1 & 1 & 1 & 1 & 1 & 1 & 1 & .39 & .40 & .41 \\
\hline LUX & .55 & .66 & .48 & .33 & .80 & 1 & 1 & 1 & 1 & 1 & .95 & .46 & .40 & .33 \\
\hline MLT & .33 & .61 & .34 & .40 & .67 & 1 & 1 & 1 & 1 & .99 & .93 & .34 & .34 & .40 \\
\hline NLD & .64 & .57 & .33 & .38 & .89 & 1 & 1 & 1 & 1 & 1 & .93 & .61 & .55 & .33 \\
\hline POL & .53 & .40 & .49 & .63 & 1 & 1 & 1 & 1 & 1 & 1 & 1 & .46 & .41 & .36 \\
\hline PRT & .75 & .44 & .66 & .50 & 1 & .91 & .99 & 1 & 1 & .99 & .98 & .58 & .41 & .33 \\
\hline ROU & .45 & .49 & .59 & .46 & 1 & .98 & .98 & 1 & 1 & 1 & 1 & .39 & .42 & .33 \\
\hline SVK & .52 & .38 & .45 & .48 & 1 & 1 & 1 & 1 & 1 & 1 & 1 & .38 & .37 & .34 \\
\hline SVN & .73 & .64 & 1 & .62 & 1 & 1 & 1 & 1 & 1 & 1 & 1 & .63 & 1 & .34 \\
\hline ESP & .62 & .35 & .48 & .43 & .98 & .97 & 1 & 1 & 1 & .98 & .97 & .71 & .57 & .33 \\
\hline SWE & .91 & .74 & .89 & .57 & 1 & 1 & 1 & .99 & 1 & .99 & .92 & 1 & 1 & .33 \\
\hline UK & .63 & .56 & .39 & .50 & .93 & 1 & .99 & 1 & 1 & 1 & .93 & .52 & .47 & .48 \\
\hline
\end{tabular}

Gri ilişkisel katsayı matrisinden yola çıkılarak formül (12) ile hesaplanan gri ilişkisel derece değerleri tablo 5 'te sunulmuştur. Gri ilişkisel derece değerlerine ulaşırken kullanılan zıtlık katsayısı 0,5 olarak kabul edilmiştir (Ayçin, 2019, s. 134-138). Elde edilen değerlerin sıralanması ile alternatiflerin ÇKKV 
problemine uygunluğuna göre ülkelerin cinsiyet eşitliği sıralamasına ulaşılmiştır.

Tablo 5. AB ülkelerinin GİA uygulaması sonucunda elde edilen cinsiyet eşitliği sıralamalarn

\begin{tabular}{|c|c|c|c|c|c|c|}
\hline Y1l & 2017 & & 2018 & & 2020 & \\
\hline Ülke & Sira & $\Gamma_{0 \mathrm{i}}$ & Sira & $\Gamma_{0 \mathrm{i}}$ & Sira & $\Gamma_{0 \mathrm{i}}$ \\
\hline AUT & 21 & 2,8947 & 21 & 2,9176 & 18 & 2,9576 \\
\hline BEL & 11 & 3,0535 & 14 & 3,0056 & 12 & 3,0321 \\
\hline BGR & 9 & 3,0816 & 10 & 3,0672 & 19 & 2,9421 \\
\hline CYP & 23 & 2,8761 & 22 & 2,8870 & 22 & 2,9038 \\
\hline CZE & 25 & 2,8561 & 24 & 2,8672 & 23 & 2,8775 \\
\hline DEU & 8 & 3,0976 & 9 & 3,0993 & 10 & 3,0677 \\
\hline DNK & 6 & 3,1697 & 6 & 3,1662 & 8 & 3,1564 \\
\hline ESP & 14 & 3,0182 & 16 & 2,9865 & 4 & 3,2147 \\
\hline EST & 15 & 3,0113 & 15 & 3,0011 & 11 & 3,0418 \\
\hline FIN & 2 & 3,4606 & 2 & 3,4148 & 1 & 3,4709 \\
\hline FRA & 5 & 3,2043 & 7 & 3,1660 & 9 & 3,1300 \\
\hline GRC & 24 & 2,8684 & 25 & 2,8642 & 24 & 2,8567 \\
\hline HRV & 18 & 2,9505 & 20 & 2,9480 & 20 & 2,9156 \\
\hline HUN & 26 & 2,8469 & 26 & 2,8445 & 25 & 2,8343 \\
\hline IRL & 4 & 3,2434 & 4 & 3,2353 & 3 & 3,2399 \\
\hline ITA & 28 & 2,7883 & 28 & 2,8144 & 27 & 2,8078 \\
\hline LTU & 10 & 3,0709 & 8 & 3,1127 & 6 & 3,1638 \\
\hline LUX & 19 & 2,9478 & 17 & 2,9850 & 14 & 3,0021 \\
\hline LVA & 7 & 3,1443 & 5 & 3,1763 & 5 & 3,2088 \\
\hline MLT & 27 & 2,8309 & 27 & 2,8179 & 26 & 2,8197 \\
\hline NLD & 16 & 3,0021 & 12 & 3,0125 & 16 & 2,9777 \\
\hline POL & 17 & 2,9626 & 18 & 2,9523 & 17 & 2,9585 \\
\hline PRT & 13 & 3,0362 & 13 & 3,0121 & 13 & 3,0216 \\
\hline ROU & 20 & 2,9284 & 19 & 2,9481 & 15 & 2,9975 \\
\hline SVK & 22 & 2,8819 & 23 & 2,8677 & 21 & 2,9058 \\
\hline SVN & 3 & 3,3762 & 3 & 3,2998 & 7 & 3,1603 \\
\hline SWE & 1 & 3,4961 & 1 & 3,5049 & 2 & 3,4240 \\
\hline UK & 12 & 3,0534 & 11 & 3,0399 & - & - \\
\hline
\end{tabular}

Tablo 5'te GİA uygulaması sonucunda AB ülkelerinin cinsiyet eşitliğine ilişkin sıralamaları verilmiştir. 2017, 2018 ve 2020 GİA sonuçlarına göre cinsiyet eşitliğinin değerlendirilmesi açısından ilk sıralarda olan üç ülke İsveç, Finlandiya ve Slovenya olurken, son üç sırada olan ülkeler ise Macaristan, Malta ve İtalya olarak belirlenmiştir. Analiz sonuçlarına göre İsveç'in 2017 ve 2018 yıllarında ilk sırada, 2020 yılında ikinci sırada yer aldığı, Finlandiya'nın 2017 ve 2018 yıllarında ikinci sırada, 2020 yılında ilk sırada yer aldığı, Slovenya'nın ise 2017 ve 2018 yılında üçüncü sırada yer alarak 2020 yılında yedinci sıraya 
gerilediği görülmektedir. Cinsiyet eşitliğinin sağlanması bakımından son üç sırada yer alan ülkelerin sıralamalarında ise üç yıl için gerçekleştirilen analizlerin tümünde aynı sırada kaldığı tespit edilmiştir.

\section{ARAS Uygulamast}

ARAS yöntemi uygulanırken karar matrisinden normalize karar matrisine ve ardından ağırlıklandırılmış normalize karar matrisine nasıl ulaşılacağına "Veri ve Yöntem" bölümünde yer verilmiştir. Buna göre karar matrisine optimal bir alternatif eklenmesi gerekmektedir. Optimal alternatif değeri her bir kriter için maksimum alternatif değeri belirlenerek hesaplanmış, sonrasında formül (13) ve formül (15) kullanılarak ağırlıklı normalize matrise ulaşılmıştır. Bu matris Tablo 6'da gösterilmektedir.

Tablo 6. ARAS yöntemi 2017 uygulaması ağırlıklı normalize karar matrisi

\begin{tabular}{lllllllllllllll}
\hline Kriter & \multicolumn{1}{l}{ EK $\left({ }^{*} \mathbf{1 0}^{-3}\right)$} & \multicolumn{1}{c}{ ED $\left({ }^{*} \mathbf{1 0}^{-3}\right)$} & \multicolumn{6}{c}{ SS $\left({ }^{*} \mathbf{* 1}^{-3}\right)$} & SG $\left(^{*} \mathbf{1 0}^{-3}\right)$ & \\
\hline Ülke & $\mathbf{1}$ & $\mathbf{2}$ & $\mathbf{3}$ & $\mathbf{4}$ & $\mathbf{5}$ & $\mathbf{1}$ & $\mathbf{2}$ & $\mathbf{3}$ & $\mathbf{4}$ & $\mathbf{1}$ & $\mathbf{2}$ & $\mathbf{1}$ & $\mathbf{2}$ & $\mathbf{3}$ \\
\hline AUT & 7 & 10 & 6 & 5 & 4 & 7 & 16 & 8 & 4 & 24 & 11 & 11 & 6 & 1 \\
BEL & 7 & 11 & 8 & 5 & 4 & 7 & 16 & 8 & 4 & 24 & 11 & 15 & 6 & 0 \\
BGR & 7 & 10 & 8 & 6 & 4 & 7 & 16 & 8 & 4 & 24 & 11 & 8 & 19 & 1 \\
HRV & 7 & 9 & 9 & 4 & 4 & 7 & 16 & 8 & 4 & 24 & 11 & 6 & 5 & 14 \\
CYP & 7 & 10 & 8 & 3 & 4 & 7 & 16 & 8 & 4 & 24 & 10 & 5 & 2 & 0 \\
CZE & 6 & 10 & 7 & 3 & 4 & 7 & 16 & 8 & 4 & 24 & 11 & 6 & 4 & 0 \\
DNK & 7 & 12 & 8 & 4 & 4 & 7 & 16 & 8 & 4 & 24 & 10 & 15 & 14 & 10 \\
EST & 7 & 11 & 7 & 6 & 4 & 7 & 16 & 8 & 4 & 24 & 11 & 9 & 8 & 2 \\
FIN & 8 & 13 & 8 & 5 & 4 & 7 & 16 & 8 & 4 & 24 & 11 & 18 & 12 & 41 \\
FRA & 7 & 8 & 9 & 5 & 4 & 7 & 16 & 8 & 4 & 24 & 11 & 16 & 19 & 2 \\
DEU & 7 & 12 & 8 & 4 & 4 & 7 & 16 & 8 & 4 & 24 & 11 & 15 & 9 & 41 \\
GRC & 6 & 11 & 8 & 3 & 4 & 6 & 16 & 8 & 4 & 24 & 11 & 6 & 5 & 0 \\
HUN & 7 & 8 & 7 & 6 & 4 & 7 & 16 & 8 & 4 & 24 & 11 & 3 & 0 & 0 \\
IRL & 6 & 12 & 7 & 6 & 4 & 7 & 16 & 8 & 4 & 24 & 10 & 7 & 7 & 92 \\
ITA & 6 & 8 & 6 & 4 & 4 & 7 & 16 & 8 & 4 & 24 & 10 & 11 & 7 & 0 \\
LVA & 7 & 11 & 8 & 9 & 4 & 7 & 16 & 8 & 4 & 24 & 11 & 5 & 6 & 33 \\
LTU & 7 & 10 & 8 & 6 & 4 & 7 & 16 & 8 & 4 & 24 & 11 & 7 & 5 & 26 \\
LUX & 7 & 12 & 7 & 2 & 4 & 7 & 16 & 8 & 4 & 24 & 10 & 10 & 5 & 0 \\
MLT & 5 & 12 & 6 & 4 & 4 & 7 & 16 & 8 & 4 & 24 & 10 & 3 & 1 & 25 \\
NLD & 7 & 11 & 6 & 3 & 4 & 7 & 16 & 8 & 4 & 24 & 10 & 14 & 11 & 0 \\
POL & 7 & 9 & 7 & 7 & 4 & 7 & 16 & 8 & 4 & 24 & 11 & 10 & 6 & 11 \\
PRT & 7 & 10 & 8 & 6 & 4 & 6 & 16 & 8 & 4 & 24 & 11 & 13 & 5 & 1 \\
ROU & 6 & 11 & 8 & 5 & 4 & 7 & 16 & 8 & 4 & 24 & 11 & 7 & 6 & 0 \\
SVK & 6 & 9 & 7 & 5 & 4 & 7 & 16 & 8 & 4 & 24 & 11 & 6 & 3 & 5 \\
SVN & 7 & 12 & 9 & 7 & 4 & 7 & 16 & 8 & 4 & 24 & 11 & 15 & 19 & 4 \\
ESP & 7 & 9 & 7 & 4 & 4 & 7 & 16 & 8 & 4 & 24 & 11 & 16 & 12 & 0 \\
SWE & 8 & 13 & 9 & 6 & 4 & 7 & 16 & 8 & 4 & 24 & 10 & 20 & 19 & 0 \\
UK & 7 & 11 & 6 & 6 & 4 & 7 & 16 & 8 & 4 & 24 & 10 & 12 & 8 & 43 \\
OPT & 8 & $\mathbf{1 3}$ & $\mathbf{9}$ & $\mathbf{9}$ & 4 & 7 & 16 & 8 & 4 & 24 & 11 & $\mathbf{2 0}$ & $\mathbf{1 9}$ & $\mathbf{9 2}$ \\
\hline
\end{tabular}


Ağırlıklı normalize karar matrisinden sonra formül (16) ile Optimallik fonksiyonu, formül (17) ile fayda derecesi hesaplanmış ve buradan hareketle alternatiflerin sıralamalarına ulaşılmıştır. Tablo 7 ülkelerin cinsiyet eşitliği s1ralamalarını göstermektedir.

Tablo 7. AB ülkelerinin ARAS uygulaması sonucunda elde edilen cinsiyet eşitliğine ait stralama sonuçlarn

\begin{tabular}{|c|c|c|c|c|c|c|c|c|c|}
\hline Y11 & 2017 & & & 2018 & & & 2020 & & \\
\hline Ülke & $\mathrm{Si}_{\mathrm{i}}$ & $\overline{K_{i}}$ & Sira & $\mathrm{S}_{\mathrm{i}}$ & $\mathbf{K}_{\mathbf{i}}$ & Sira & $\mathrm{S}_{\mathrm{i}}$ & $\mathbf{K}_{\mathbf{i}}$ & Sira \\
\hline AUT & 0,1188 & 0,4892 & 20 & 0,1208 & 0,5044 & 20 & 0,1313 & 0,5295 & 14 \\
\hline BEL & 0,1252 & 0,5153 & 17 & 0,1247 & 0,5203 & 18 & 0,1310 & 0,5286 & 15 \\
\hline BGR & 0,1311 & 0,5395 & 11 & 0,1307 & 0,5456 & 12 & 0,1246 & 0,5027 & 21 \\
\hline CYP & 0,1087 & 0,4475 & 27 & 0,1082 & 0,4514 & 27 & 0,1134 & 0,4575 & 26 \\
\hline CZE & 0,1103 & 0,4542 & 26 & 0,1115 & 0,4653 & 26 & 0,1183 & 0,4773 & 24 \\
\hline DEU & 0,1686 & 0,6940 & 3 & 0,1679 & 0,7010 & 4 & 0,1801 & 0,7264 & 3 \\
\hline DNK & 0,1439 & 0,5923 & 9 & 0,1432 & 0,5978 & 8 & 0,1471 & 0,5936 & 7 \\
\hline ESP & 0,1286 & 0,5295 & 14 & 0,1284 & 0,5360 & 14 & 0,1448 & 0,5842 & 8 \\
\hline EST & 0,1234 & 0,5080 & 19 & 0,1259 & 0,5255 & 17 & 0,1361 & 0,5489 & 12 \\
\hline FIN & 0,1788 & 0,7361 & 2 & 0,1758 & 0,7339 & 2 & 0,1841 & 0,7428 & 2 \\
\hline FRA & 0,1395 & 0,5742 & 10 & 0,1395 & 0,5823 & 9 & 0,1419 & 0,5726 & 9 \\
\hline GRC & 0,1119 & 0,4605 & 25 & 0,1126 & 0,4702 & 25 & 0,1169 & 0,4716 & 25 \\
\hline HRV & 0,1266 & 0,5212 & 15 & 0,1283 & 0,5356 & 15 & 0,1374 & 0,5544 & 11 \\
\hline HUN & 0,1049 & 0,4318 & 28 & 0,1058 & 0,4415 & 28 & 0,1101 & 0,4441 & 27 \\
\hline IRL & 0,2095 & 0,8624 & 1 & 0,2051 & 0,8563 & 1 & 0,2139 & 0,8628 & 1 \\
\hline ITA & 0,1148 & 0,4727 & 24 & 0,1184 & 0,4944 & 21 & 0,1210 & 0,4880 & 23 \\
\hline LTU & 0,1441 & 0,5931 & 8 & 0,1467 & 0,6125 & 7 & 0,1541 & 0,6218 & 5 \\
\hline LUX & 0,1158 & 0,4768 & 22 & 0,1167 & 0,4871 & 23 & 0,1226 & 0,4944 & 22 \\
\hline LVA & 0,1523 & 0,6270 & 5 & 0,1508 & 0,6293 & 5 & 0,1642 & 0,6625 & 4 \\
\hline MLT & 0,1291 & 0,5314 & 13 & 0,1314 & 0,5486 & 11 & 0,1384 & 0,5583 & 10 \\
\hline NLD & 0,1260 & 0,5188 & 16 & 0,1277 & 0,5332 & 16 & 0,1266 & 0,5109 & 18 \\
\hline POL & 0,1298 & 0,5344 & 12 & 0,1292 & 0,5395 & 13 & 0,1349 & 0,5444 & 13 \\
\hline PRT & 0,1245 & 0,5125 & 18 & 0,1236 & 0,5159 & 19 & 0,1295 & 0,5224 & 17 \\
\hline ROU & 0,1159 & 0,4769 & 21 & 0,1169 & 0,4879 & 22 & 0,1252 & 0,5053 & 20 \\
\hline SVK & 0,1156 & 0,4758 & 23 & 0,1146 & 0,4783 & 24 & 0,1253 & 0,5054 & 19 \\
\hline SVN & 0,1465 & 0,6029 & 7 & 0,1392 & 0,5810 & 10 & 0,1297 & 0,5232 & 16 \\
\hline SWE & 0,1472 & 0,6060 & 6 & 0,1488 & 0,6211 & 6 & 0,1506 & 0,6074 & 6 \\
\hline \multirow[t]{2}{*}{ UK } & 0,1669 & 0,6869 & 4 & 0,1687 & 0,7043 & 3 & & & \\
\hline & OPT & 0.2429 & & OPT & 0.2396 & & OPT & 0.2479 & \\
\hline
\end{tabular}

\section{COPRAS Uygulamast}

COPRAS yöntemi uygulanırken formül (18) ile normalizasyon ve formül (20) ile ağırlıklandırma adımlarının ardından 2017 yılının verileri ile COPRAS uygulamasının ağırlıklandırılmış normalize karar matrisi Tablo 8'de sunulmuştur. 
Tablo 8. 2017 yılı COPRAS uygulaması ağırlıklandırılmış normalize karar matrisi

\begin{tabular}{|c|c|c|c|c|c|c|c|c|c|c|c|c|c|c|}
\hline \multirow{2}{*}{$\begin{array}{l}\text { Kriter } \\
\text { Ülkke }\end{array}$} & \multicolumn{5}{|c|}{ EK $\left({ }^{*} 10^{-3}\right)$} & \multicolumn{4}{|c|}{$\operatorname{ED}\left({ }^{*} 10^{-3}\right)$} & \multicolumn{2}{|c|}{ SS $\left({ }^{*} 10^{-3}\right)$} & \multicolumn{3}{|c|}{ SG $\left({ }^{*} 10^{-3}\right)$} \\
\hline & 1 & 2 & 3 & 4 & 5 & 1 & 2 & 3 & 4 & 1 & 2 & 1 & 2 & 3 \\
\hline AUT & 7 & 11 & 6 & 5 & 4 & 7 & 16 & 8 & 4 & 25 & 11 & 12 & 6 & 2 \\
\hline BEL & 7 & 12 & 8 & 5 & 4 & 7 & 16 & 8 & 4 & 25 & 11 & 17 & 6 & 0 \\
\hline BGR & 7 & 10 & 8 & 6 & 4 & 7 & 16 & 8 & 4 & 25 & 11 & 8 & 20 & 1 \\
\hline HRV & 7 & 10 & 9 & 4 & 4 & 7 & 16 & 8 & 4 & 25 & 11 & 6 & 5 & 17 \\
\hline CYP & 7 & 11 & 8 & 4 & 4 & 7 & 16 & 8 & 4 & 25 & 11 & 6 & 2 & 0 \\
\hline CZE & 7 & 10 & 7 & 4 & 4 & 7 & 16 & 8 & 4 & 25 & 11 & 7 & 4 & 0 \\
\hline DNK & 8 & 12 & 8 & 4 & 4 & 7 & 16 & 8 & 4 & 25 & 11 & 16 & 15 & 13 \\
\hline EST & 7 & 12 & 8 & 6 & 4 & 7 & 16 & 8 & 4 & 25 & 11 & 10 & 8 & 2 \\
\hline FIN & 8 & 14 & 9 & 5 & 4 & 7 & 16 & 8 & 4 & 25 & 11 & 20 & 13 & 51 \\
\hline FRA & 7 & 8 & 9 & 5 & 4 & 7 & 16 & 8 & 4 & 25 & 11 & 17 & 20 & 3 \\
\hline DEU & 7 & 12 & 8 & 4 & 4 & 7 & 16 & 8 & 4 & 25 & 11 & 16 & 10 & 52 \\
\hline GRC & 6 & 11 & 8 & 4 & 4 & 7 & 16 & 8 & 4 & 25 & 11 & 6 & 5 & 0 \\
\hline HUN & 7 & 9 & 8 & 7 & 4 & 7 & 16 & 8 & 4 & 25 & 11 & 3 & 0 & 0 \\
\hline IRL & 7 & 12 & 7 & 6 & 4 & 7 & 16 & 8 & 4 & 25 & 11 & 8 & 7 & 115 \\
\hline ITA & 6 & 9 & 6 & 4 & 4 & 7 & 16 & 8 & 4 & 25 & 11 & 12 & 8 & 0 \\
\hline LVA & 8 & 12 & 9 & 9 & 4 & 7 & 16 & 8 & 4 & 25 & 11 & 5 & 6 & 41 \\
\hline LTU & 8 & 11 & 9 & 7 & 4 & 7 & 16 & 8 & 4 & 25 & 11 & 7 & 6 & 33 \\
\hline LUX & 7 & 13 & 8 & 2 & 4 & 7 & 16 & 8 & 4 & 25 & 11 & 11 & 5 & 0 \\
\hline MLT & 5 & 12 & 6 & 4 & 4 & 7 & 16 & 8 & 4 & 25 & 11 & 4 & 1 & 32 \\
\hline NLD & 7 & 12 & 6 & 4 & 4 & 7 & 16 & 8 & 4 & 25 & 11 & 15 & 12 & 0 \\
\hline POL & 7 & 10 & 8 & 7 & 4 & 7 & 16 & 8 & 4 & 25 & 11 & 11 & 6 & 13 \\
\hline PRT & 8 & 11 & 9 & 6 & 4 & 7 & 16 & 8 & 4 & 25 & 11 & 14 & 6 & 1 \\
\hline ROU & 6 & 11 & 8 & 5 & 4 & 7 & 16 & 8 & 4 & 25 & 11 & 7 & 6 & 0 \\
\hline SVK & 7 & 9 & 7 & 6 & 4 & 7 & 16 & 8 & 4 & 25 & 11 & 7 & 3 & 6 \\
\hline SVN & 7 & 13 & 10 & 7 & 4 & 7 & 16 & 8 & 4 & 25 & 11 & 16 & 20 & 5 \\
\hline ESP & 7 & 9 & 8 & 5 & 4 & 7 & 16 & 8 & 4 & 25 & 11 & 17 & 13 & 0 \\
\hline SWE & 8 & 13 & 10 & 7 & 4 & 7 & 16 & 8 & 4 & 25 & 11 & 21 & 20 & 0 \\
\hline UK & 7 & 12 & 7 & 6 & 4 & 7 & 16 & 8 & 4 & 25 & 11 & 13 & 9 & 54 \\
\hline
\end{tabular}

Kullanılan kriterlerin tamamı fayda yönlü olduğundan dolayı formül (21) ile normalize indeksler toplanmış, formül (23) ile önem derecelerine ulaşılmış, ardından performans indeksleri belirlenmiş ve sonuç olarak sıralamalara ulaşılmıştır. Tablo 9, 2017, 2018 ve 2020 yılları için COPRAS uygulama sonuçlarına göre $\mathrm{AB}$ ülkelerinin cinsiyet eşitliği sıralamalarını göstermektedir. 
AB Ülkelerinin Küresel Cinsiyet Ayrımının Kadınlar Açısından Gri İlişkisel Analiz, ARAS ve COPRAS Yöntemleri ile Değerlendirilmesi

Tablo 9. AB ülkelerinin COPRAS uygulaması sonucunda elde edilen cinsiyet eşitliğine ait stralama sonuçları

\begin{tabular}{|c|c|c|c|c|c|c|c|c|c|}
\hline Yil & 2017 & & & 2018 & & & 2020 & & \\
\hline Ülke & $\mathbf{Q}_{\mathrm{i}}$ & $P_{i}$ & Sira & $\mathrm{Q}_{\mathrm{i}}$ & $\mathbf{P}_{\mathbf{i}}$ & Sira & $Q_{i}$ & $P_{i}$ & Sira \\
\hline AUT & 0,1243 & 52,1410 & 20 & 0,1265 & 54,6459 & 20 & 0,1378 & 56,5719 & 14 \\
\hline BEL & 0,1308 & 54,8342 & 17 & 0,1303 & 56,2840 & 18 & 0,1371 & 56,2932 & 15 \\
\hline BGR & 0,1374 & 57,6261 & 13 & 0,1371 & 59,2045 & 12 & 0,1304 & 53,5376 & 21 \\
\hline CYP & 0,1131 & 47,4469 & 27 & 0,1126 & 48,6258 & 27 & 0,1182 & 48,5289 & 26 \\
\hline CZE & 0,1150 & 48,2100 & 26 & 0,1162 & 50,1875 & 26 & 0,1235 & 50,7092 & 24 \\
\hline DEU & 0,1851 & 77,6099 & 3 & 0,1842 & 79,5489 & 4 & 0,1995 & 81,8942 & 3 \\
\hline DNK & 0,1528 & 64,0879 & 9 & 0,1520 & 65,6323 & 8 & 0,1564 & 64,2182 & 7 \\
\hline ESP & 0,1346 & 56,4490 & 15 & 0,1345 & 58,0817 & 15 & 0,1521 & 62,4225 & 8 \\
\hline EST & 0,1293 & 54,2052 & 19 & 0,1324 & 57,1828 & 17 & 0,1440 & 59,0982 & 12 \\
\hline FIN & 0,1958 & 82,1272 & 2 & 0,1918 & 82,8275 & 2 & 0,2019 & 82,8572 & 2 \\
\hline FRA & 0,1467 & 61,5274 & 10 & 0,1468 & 63,4055 & 9 & 0,1494 & 61,3277 & 10 \\
\hline GRC & 0,1166 & 48,9005 & 25 & 0,1175 & 50,7319 & 25 & 0,1220 & 50,0998 & 25 \\
\hline HRV & 0,1350 & 56,5971 & 14 & 0,1370 & 59,1737 & 13 & 0,1479 & 60,7267 & 11 \\
\hline HUN & 0,1091 & 45,7436 & 28 & 0,1100 & 47,5287 & 28 & 0,1147 & 47,0813 & 27 \\
\hline IRL & 0,2385 & 100,0000 & 1 & 0,2315 & 100,0000 & 1 & 0,2436 & 100,0000 & 1 \\
\hline ITA & 0,1199 & 50,2771 & 24 & 0,1238 & 53,4798 & 21 & 0,1265 & 51,9306 & 23 \\
\hline LTU & 0,1559 & 65,3917 & 6 & 0,1588 & 68,5760 & 6 & 0,1686 & 69,2131 & 5 \\
\hline LUX & 0,1208 & 50,6507 & 23 & 0,1217 & 52,5836 & 23 & 0,1280 & 52,5488 & 22 \\
\hline LVA & 0,1660 & 69,6038 & 5 & 0,1635 & 70,6176 & 5 & 0,1789 & 73,4466 & 4 \\
\hline MLT & 0,1399 & 58,6537 & 11 & 0,1424 & 61,4985 & 11 & 0,1507 & 61,8706 & 9 \\
\hline NLD & 0,1318 & 55,2698 & 16 & 0,1337 & 57,7433 & 16 & 0,1325 & 54,3750 & 18 \\
\hline POL & 0,1378 & 57,7793 & 12 & 0,1369 & 59,1520 & 14 & 0,1434 & 58,8588 & 13 \\
\hline PRT & 0,1303 & 54,6228 & 18 & 0,1294 & 55,8717 & 19 & 0,1357 & 55,7025 & 17 \\
\hline ROU & 0,1208 & 50,6732 & 22 & 0,1221 & 52,7489 & 22 & 0,1316 & 54,0230 & 20 \\
\hline SVK & 0,1214 & 50,9214 & 21 & 0,1203 & 51,9590 & 24 & 0,1319 & 54,1632 & 19 \\
\hline SVN & 0,1544 & 64,7312 & 8 & 0,1466 & 63,3004 & 10 & 0,1363 & 55,9666 & 16 \\
\hline SWE & 0,1544 & 64,7470 & 7 & 0,1562 & 67,4869 & 7 & 0,1581 & 64,8945 & 6 \\
\hline UK & 0,1836 & 77,0050 & 4 & 0,1854 & 80,0739 & 3 & & & \\
\hline
\end{tabular}

ARAS ve COPRAS ile AB ülkelerinin cinsiyet eşitliği bakımından sıralamalarının yapıldığı analiz sonuçlarına göre Tablo 9'da en başarılı iki sırada yer alan İrlanda ve Finlandiya'nın sıralamalarının 2017, 2018 ve 2020 uygulamalarında ayn kaldığ 1 görülmüştür. Tablo 9'da üçüncü sırada yer alan Almanya'nın ise hem ARAS hem de COPRAS yönteminde 2017 ve 2020 yılında üçüncü sırayı aldığı görülürken, her iki yöntemde de 2018 yılında üçüncü sıraya İngiltere'nin yükselmesi ile Almanya'nın dördüncü sıraya gerilediği tespit edilmiştir. 2017 ve 2018 yıllarında ARAS ve COPRAS uygulamaları sonucunda cinsiyet eşitliği bakımından sondan üçüncü sıralamada Çek Cumhuriyeti, Kıbrıs ve Macaristan yer almıştır. 2020 yılında ise hem ARAS hem de 
COPRAS uygulamasında Çek Cumhuriyeti bir üst sıralamaya çıkarak Yunanistan'ın önüne geçmiştir.

\section{GİA, ARAS ve COPRAS Yöntemlerinin Stralama Sonuçlarının Karşılaştırılması}

Şekil 3'te kullanılan yöntemlerin 2017 yılına ait cinsiyet eşitliği sıralama sonuçları gösterilmiştir.

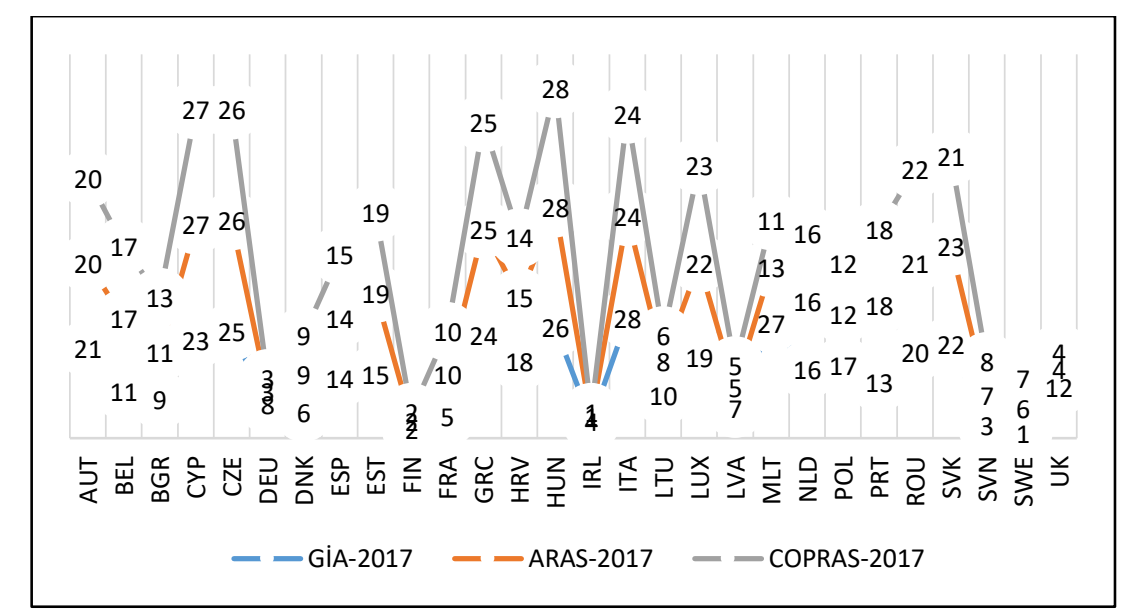

Şekil 3. 2017 yılına ait kullanılan yöntemlerin cinsiyet eşitliği sıralama sonuçlarının karşılaştırması

Şekil 4'te kullanılan yöntemlerin 2018 yılına ilişkin cinsiyet eşitliği sıralama sonuçları karşılaştırılarak gösterilmiştir. 


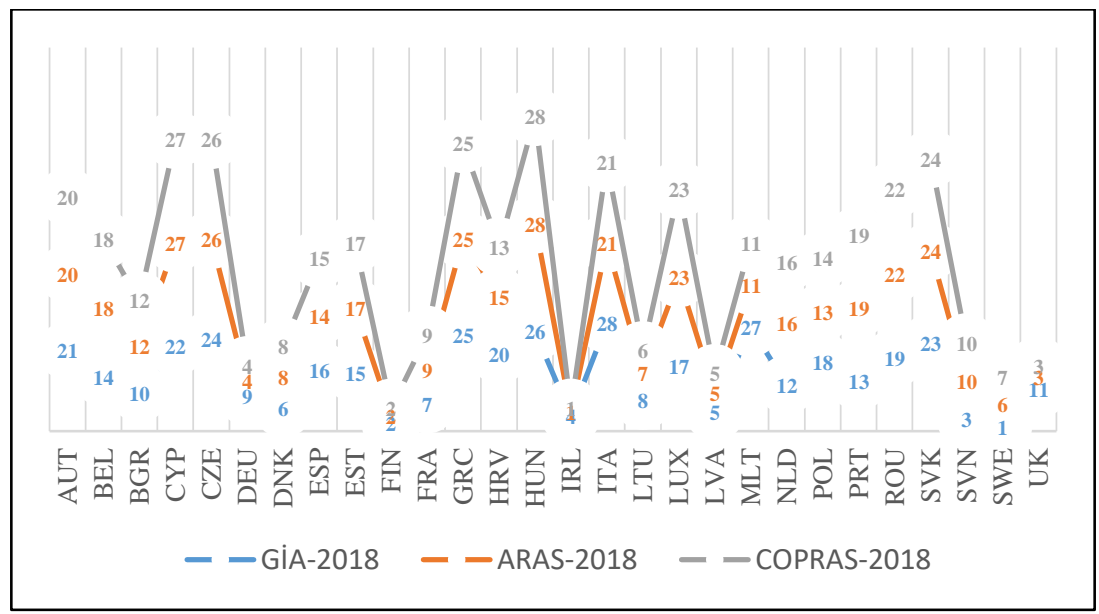

Şekil 4. 2018 yılına ait kullanılan yöntemlerin cinsiyet eşitliği sıralama sonuçlarının karşılaştırması

Şekil 5'te kullanılan yöntemlerin 2020 yılının cinsiyet eşitliği karşılaştırmalı sıralama sonuçları verilmiştir.

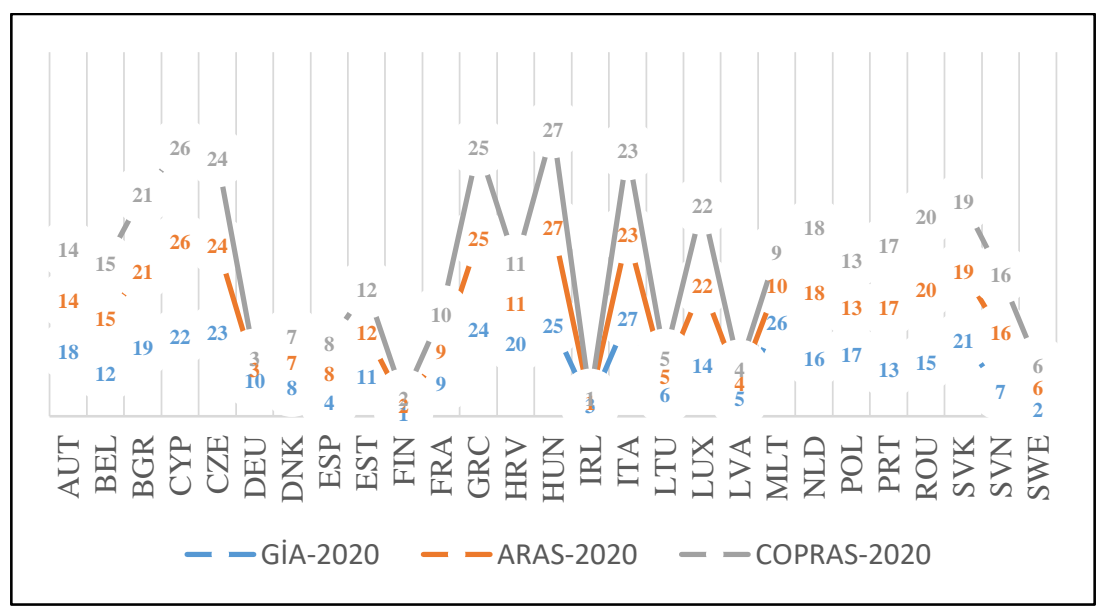

Şekil 5. 2020 yılına ait kullanılan yöntemlerin cinsiyet eşitliği sıralama sonuçlarının karşılaştırması 
Şekil 3-4-5 incelendiğinde, ARAS ve COPRAS yöntemleri ile GİA yöntemi sonucunda elde edilen sıralama sonuçları arasında farklılığın olduğu görülmekte, bu durum uygulamaların yapısal farklılığından kaynaklanmaktadır.

Çalışmada son olarak uygulanan üç yöntemden hangisinin gerçek sıralamalara daha uygun olduğunu belirlemek için Küresel Cinsiyet Ayrımı Raporu'nda yer alan siralamalar ile GİA, ARAS ve COPRAS uygulamalarından elde edilen sıralamalara Spearman korelasyon analizi uygulanmıştır. Spearman Korelasyon analizi sonuçları Tablo 10’ da gösterilmiştir.

Tablo 10. GİA, ARAS, COPRAS yöntemleri için Spearman korelasyon analizi sonuçlan

\begin{tabular}{|c|c|c|c|c|}
\hline 2017 yill & WEF-2017 & GİA-2017 & ARAS-2017 & COPRAS-2017 \\
\hline WEF-2017 & 1 & & & \\
\hline GİA-2017 &, $974^{* *}$ & 1 & & \\
\hline ARAS-2017 & $883^{* *}$ &, $852^{* *}$ & 1 & \\
\hline COPRAS-2017 & $847^{* *}$ &, $818^{* * *}$ & ,994** & 1 \\
\hline \multicolumn{5}{|l|}{${ }^{* *} p<0,01$} \\
\hline 2018 yilı & WEF-2018 & GİA-2018 & ARAS-2018 & COPRAS-2018 \\
\hline WEF-2018 & 1 & & & \\
\hline GİA-2018 & , $956^{* *}$ & 1 & & \\
\hline ARAS-2018 & $868^{* *}$ &, $810^{* *}$ & 1 & \\
\hline COPRAS-2018 & $858^{* *}$ &, $802^{* *}$ & ,998** & 1 \\
\hline \multicolumn{5}{|l|}{${ }^{* *} \mathrm{p}<0,01$} \\
\hline 2020 yill & WEF-2020 & GİA-2020 & ARAS-2020 & COPRAS-2020 \\
\hline WEF-2020 & 1 & & & \\
\hline GİA-2020 &, $930^{* *}$ & 1 & & \\
\hline ARAS-2020 & $846^{* *}$ &, $785^{* *}$ & 1 & \\
\hline $\begin{array}{l}\text { COPRAS-2020 } \\
{ }_{* *} \mathrm{p}<0,01\end{array}$ &, $836^{* *}$ &, $775^{* *}$ & ,999** & 1 \\
\hline
\end{tabular}

Tablo 10'da görüldüğü üzere, Spearman korelasyon analizi sonucunda Küresel Cinsiyet Ayrımı Raporu'nun gerçek sıralamasına ilişkin olarak korelasyon katsayıları incelendiğinde, 2017 yılına ait korelasyon katsayısı GİA için $[\mathrm{r}=, 974 ; \mathrm{p}<0,01]$, ARAS için [r=,883; $\mathrm{p}<0,01]$ ve COPRAS için $[\mathrm{r}=, 847$; p<0,01] olarak ölçülmüştür. 2018 yılı için gerçek cinsiyet eşitliği sıralama sonucuna ilişkin korelasyon katsayıları GİA için [r=,956; $\mathrm{p}<0,01]$, ARAS için $[\mathrm{r}=, 868 ; \mathrm{p}<0,01]$ ve COPRAS için $[\mathrm{r}=0,858 ; \mathrm{p}<0,01] ; 2020$ yılı için korelasyon katsayısı GİA için [r=0,930; $p<0,01]$, ARAS için [r=,846; $\mathrm{p}<0,01]$ ve COPRAS için $[r=, 836 ; p<0,01]$ olarak hesaplanmıştır. Böylece üç yıl için yöntemlerin s1ralama başarıları karşılaştıııldığında, GİA yönteminin ARAS ve COPRAS yöntemlerine göre, ARAS yönteminin de COPRAS yöntemine göre daha başarılı sıralama sonucuna sahip olduğu belirlenmiştir. 


\section{Sonuç}

Bireylerin sadece cinsiyetlerinden dolayı firsatlara ve kaynaklara eşit bir şekilde ulaşamaması, bireysel varlığını topluma hissettirememesi, sağlık ve eğitim gibi konularda diğer cinsten geri kalmasını ifade eden cinsiyet eşitsizliğinin artış gösterdiği ülkelerin demokrasisi ve ekonomi alanı olumsuz yönde etkilenmektedir.

Toplumsal cinsiyet kavramının kaynağı olan kültürel cinsiyet rolleri erkekler için ev ekonomisi görevleri ve kadınlar için ev içi görevleri olarak düşünülmekte, bu durum iş hayatında aktif olan kadınların ev içi görevleri nedeniyle iş yerinde pasifleştiği bilinmektedir (Vargel Pehlivan, 2017, p. 500). Cinsiyet eşitsizliği, kadınların yalnızca iş hayatına değil, eğitim ve sağlık gibi insani ihtiyaçlarını da etkileyebilmektedir. Dünya Ekonomik Formu gibi çeşitli kuruluşlar cinsiyet eşitliğine yönelik raporlar hazırlamakta, ülkelerin cinsiyet eşitliği konusundaki gelişmelerine veya gerilemelerine dikkat çekerek ülkelere öneriler sunmakta ve katkı sağlamaktadırlar.

Bu doğrultuda çalışmada Dünya Ekonomik Formu'nun hazırladığı verileri kullanarak $\mathrm{AB}$ ülkelerinin cinsiyet eşitliklerinin değerlendirilmesi amaçlanmıştır. Bu çalışmada 2017, 2018, 2020 yılına ait Dünya Ekonomik Forumu tarafından hazırlanan Küresel Cinsiyet Ayrımı Raporu'nun verilerine GİA, ARAS ve COPRAS yöntemleri uygulanarak, $A B$ üye ülkelerinin cinsiyet eşitliği açısından değerlendirilmesi yapılmış ve sıralama sonuçları açıklanmaya çalışılmıştır. Yöntemlerin sıralama başarılarını değerlendirmek için ülkelerin gerçek cinsiyet eşitliği sıralama sonuçları ile yöntemlerin sıralama sonuçları arasındaki ilişkiyi ölçmede Spearman korelasyon analizi gerçekleştirilmiştir. Yapılan Spearman korelasyon analizi sonucunda GİA yönteminin ARAS yöntemine göre ve ARAS yönteminin COPRAS yöntemine göre daha başarılı sıralama sonuçları verdiği ve gerçek sıralama sonuçlarına daha iyi uyum sağladığ tespit edilmiştir.

Yapılan analiz sonuçlarında; 2017, 2018 ve 2020 yılı dönemine ilişkin cinsiyet eşitliği sıralamasında ARAS ve COPRAS yöntemine göre İrlanda, Finlandiya ve Almanya'nın ilk üç sıralamada ve Macaristan, Kıbrıs, Çek Cumhuriyeti'nin son üç sıralamada yer aldığı ortaya çıkmıştır. Buna karşın GİA yöntemine göre İsveç, Finlandiya ve Slovenya'nın ilk üç sıralamada ve İtalya, Malta ve Macaristan'ın son üç sıralamada yer aldığı tespit edilmiş̧ir. AB ül- 
kelerinin cinsiyet eşitliğine yönelik yöntemler arası sıralama sonuçları karşılaştırıldığında, kullanılan yöntemlerin sıralama sonuçlarındaki farklılığın nedeninin yöntemlerin yapısal farklılıkları ve kriterlerin değişkenliğinden kaynakladığ belirlenmiştir.

Sonuç itibariyle, $\mathrm{AB}$ ülkelerinin cinsiyet eşitliği sıralamasının belirlenmesine yönelik bu çalışmanın literatüre ve araştırmacılara katkı sağlayacağı beklenmektedir. Ayrıca bundan sonra yapılacak cinsiyet eşitliği değerlendirilmesine yönelik çalışmalarda kriter ağırlıklarının belirlenerek farklı ÇKKV yöntemleri uygulanıp bu çalışmanın sonuçları ile mukayese edilebilir. 


\title{
EXTENDED ABSTRACT
}

\section{Evaluation of EU Countries in the Global Gender Gap by Grey Relational Analysis, ARAS and COPRAS Methods for Women}

\author{
Emre Yakut - Özlem Kuru \\ Osmaniye Korkut Ata University
}

The term gender has been introduced to the literature by Ann Oakley (Şafak Uzun, 2019). Ann Oakley (1985, p. 16) describes the concept of gender as a matter of culture that refers to the social classification into 'masculine' and 'feminine'.

Vatandas (2007, p. 31) states that discrimination arises mainly out of prejudice. Sex discrimination, on the other hand, evolves into a social form through prejudice arising from various discourses, opinions, and experiences.

The European Institute for Gender Equality (EIGE) defines gender inequality as a legal, social and cultural situation in which sex and/or gender determine different rights and dignity for women and men, which are reflected in their unequal access to or enjoyment of rights, as well as the assumption of stereotyped social and cultural roles (EIGE, 2020).

It is obvious that gender inequality, as a result of patriarchal structure accepted in societies, is a situation that affects women more. The state of inequality may differ by the development levels of the countries (Bozkaya, 2016). According to the data of the United Nations Department of Economic and Social Affairs (UN DESA, 2019), approximately 49.5 percent of the world's population consists of women. Hereunder, passivating almost half of the population by suppressing and the negative effects of removing them from production under the pretense of various obstacles are reasonable situations. Üstün (2011) utters that gender inequality is not only a social situation affecting women and girls, but an obstacle to democratization and development. For the purpose of ensuring that countries become aware of their places globally to minimize these negative effects, various studies have been conducted to evaluate gender inequality. 
This study evaluates the rankings of the member countries of the European Union (EU) on gender equality. The data of the study were obtained from the Global Gender Gap Report prepared by the World Economic Forum (WEF) using annual data. A data set was created by using the country data in the index that took place in 2017, 2018, and 2020 issues of the relevant report. The index benchmarks were classified under four main titles: "Economic Participation and Opportunity", "Educational Attainment", "Health and Survival", and "Political Empowerment". Although the weights of all indexes are equal, the weights of the subindexes under the index change. The weights of the indexes take the same values for all years as stated in the WEF report. Index values in the WEF report were obtained with the ratio of women to men for the relevant index (WEF, 2017; WEF, 2018; WEF, 2020). Based on these data, it was tried to reach the EU member countries' rankings regarding gender equality by using Grey Relational Analysis (GRA), ARAS and COPRAS methods.

Grey Relational Analysis (GRA) is a decision-making method that can be applied to analyze the relationships between multiple factors and variables (Wang, Zhu and Wang, 2016). The application of GRA, which starts with creating the decision matrix, continues with the steps of creating the reference series and comparison matrix, normalized decision matrix, absolute value matrix, and grey relational coefficients matrix, and consequently, the rankings are reached with the determination of the gray relational grades (Ayçin, 2019, p. 134-138).

The ARAS (Additive Ratio Assessment) method was introduced in a study carried out by Turskis and Zavadskas (2010). According to ARAS, the utility function value of the alternative in an MCDM problem is directly proportional to the relative effect of the values and weights of the index. The utility function values of the solution alternatives of the problem are compared with the utility function value of an optimal alternative added by the researcher and thus, the result is attained (Turskis and Zavadskas, 2010; Yıldırım, 2015.b).

COPRAS (COmplex PRoportional ASsessment) is a multi-criteria decision-making method introduced to the literature by Zavadskas, Kaklauskas, and Sarka (1994). Similar to other methods, implementation steps begin with the creation, normalization, and weighting of the normalized decision matrix. 
Then weighted normalized indices are added, the importance levels of decision alternatives are calculated, and the application ends with reaching the performance indexes of the alternatives (Ayçin, 2019, p. 64).

Following the analysis applied to the data, 9 different sequences were obtained for three different methods for 2017, 2018 and 2020. To evaluate the success of the methods, the Spearman's correlation analysis was performed to measure the relationship between the actual ranking results in the WEF reports and the ranking results of the methods.

As a result of the Spearman's correlation analysis, the 2017 correlation coefficients were measured as follows: $r=0,974 ; p<0,01$ for GRA; $r=0,883 ; p<0,01$ for ARAS; and $\mathrm{r}=0,847 ; \mathrm{p}<0,01$ for COPRAS. The 2018 correlation coefficients, on the other hand, were measured as follows: $\mathrm{r}=0,956 ; \mathrm{p}<0,01$ for GRA; $\mathrm{r}=0,868 ; \mathrm{p}<0,01$ for ARAS; and $\mathrm{r}=0,868 ; \mathrm{p}<0,01$ for COPRAS, while these values were found for 2020 as follows: $r=0,930$; $p<0,01$ for GRA; $r=0,846$; $p<0,01$ for ARAS; and $\mathrm{r}=0,836 ; \mathrm{p}<0,01$ for COPRAS. Thus, when the ranking successes for 3 years were compared, GRA method was found to be more successful than the ARAS and COPRAS methods, while the ARAS method was found to be more successful than the COPRAS method.

The reason for the difference in the ranking results of EU countries in terms of gender equality method is due to the structural differences of the methods.

In conclusion, this study, which aims to determine the gender equality ranking of the EU countries, is expected to contribute to the literature and researchers. Besides, in future studies evaluating gender equality, different MCDM methods can be applied by determining the index weights and the results obtained can be compared with the results of this study.

\section{Kaynakça / References}

Alinezhad, A. ve Khalili, J. (2019). New methods and applications in Multiple Attribute Decision Making (MADM). Cham: Springer.

Ayçin, E. (2019). Çok Kriterli Karar Verme Bilgisayar Uygulamalı Çözümler. Ankara: Nobel.

Bağdatl Kalkan, S. (2018). Ranking of countries with grey relational analysis method according to global gender gap index. International Social Sciences Studies Journal, 4(28), 6348-6355. 
Başdeğirmen, A. ve Işıldak, B. (2018). Ulaştırma sektöründe faaliyet gösteren işletmelerin performanslarının gri ilişkisel analiz ile değerlendirilmesi. Süleyman Demirel Üniversitesi İktisadi ve İdari Bilimler Fakültesi Dergisi, 23(2), 563-577.

United Nations (UN) Department of Economic and Social Affairs (2019). 2019 Revision of World Population Prospects.

Bora, A. (2012). Toplumsal cinsiyete dayalı ayrmmcılı. Ayrmmcıllk: Çok Boyutlu Yaklaşımlar. (Der: K. Çayır ve M. Ayan Ceyhan) İstanbul bilgi üniversitesi yayınları.

Bozkaya, G. (2016). Sosyal koruma harcamalar ve cinsiyet eşitsizliğinin yoksulluk üzerine etkisi: OECD ülkeleri için bir uygulama. Doktora Tezi. Kahramanmaraş: Kahramanmaraş Sütçü İmam Üniversitesi.

Deng, J. (1982). Control problems of grey systems. Systems and Control Letters, 1(5), 288294.

Deng, J. (1989). Introduction to grey system Theory. The Journal of Grey System, 1(1), 124.

Durgun, C. ve Oğuz Gök, G. (2017). Toplumsal cinsiyet eşitsizliği bağlamında BRICS \& G7 ülkelerinin karşılaştırmalı analizi. Beykent Üniversitesi Sosyal Bilimler Dergisi, $10(2), 20-32$.

Emovon, I. ve Mgbemena, C. O. (2018). Machinery/Service system scheduled replacement time determination: a combine weighted aggregated sum product assessment, additive ratio assessment and age replacement model approach. International Journal of Integrated Engineering, 10(1), 169-175.

European Institute for Gender Equality [EIGE] (2020). Gender Inequality. https://eige.europa.eu/thesaurus/terms/1182 adresinden erişilmiştir.

European Union [EU] (2020). The 27 member countries of the EU. https:/europa.eu/european-union/about-eu/countries en\#the-27-member-countries-of-the-eu adresinden erişilmiştir.

Gençoğlu, P ve Kuşkaya, S. (2016). Küresel cinsiyet uçurumu (global gender gap) açsindan Avrupa ve Orta Asya ülkelerinin değerlendirilmesi: istatistiksel bir analiz. Uluslararası Sosyal Araştırmalar Dergisi, 9(46), 696-705.

Kara, E. (2019). The effect of gender in the relationship of career development and job satisfaction for female employees. Uluslararası İktisadi ve İdari İncelemeler Dergisi, 24, 59-72.

Kharchenko, E. I. (2016). Gender inequality indices for the European partnership countries comparison. Rudn Journal of Sociology-Vestnik Rossiiskogo Universiteta Druzhby Narodov Seriya Sotsiologiya, 16(2), 323-335.

Koca, G. Ş. (2018). Düşük insani gelişmeye sahip olan ülkelerin cinsiyet eşitsizliğinin incelenmesi. Journal of Social and Humanities Sciences Research, 5(31), 4620-4627. 
Kose, E., Vural, D. ve Canbulut, G. (2020), The most livable city selection in Turkey with the grey relational analysis. Grey Systems: Theory and Application. https://doi.org/10.1108/GS-04-2020-0042

Liu, S. ve Lin, Y. (2006). Grey information: Theory and practical applications. London: Springer.

Liu, S., Forrest, J. ve Yang, Y. (2013). Advances in grey system research. The Journal of Grey System, 25(2), 1-18.

Macáková, L. (2016). Gender discrimination in the Czech Republic and other VISEGRAD countries according to GGGI. The 10th International Days of Statistics and Economics, September 8-10, Prague.

Oakley, A. (1985). Towards a new society: Sex, gender and society. Hants: Gower Publishing Company.

Özbek, A. ve Demirkol, İ. (2019). Avrupa Birliği Ülkeleri ile Türkiye'nin ekonomik göstergelerinin karşlaştırılması. Yönetim ve Ekonomi, 26(1), 71-92.

Pitchipoo, P., Vincent, D. S., Rajini, N. ve Rajakarunakaran, S. (2014). COPRAS decision model to optimize blind spot in heavy vehicles: A comparative perspective. Procedia Engineering, 97, 1049-1059.

Roy, J., Sharma, H. K., Kar, S., Zavadskas, E. K. ve Saparauskas, J. (2019). An extended COPRAS model for multi-criteria decision-making problems and its application in web-based hotel evaluation and selection. Economic Research-Ekonomska Istraživanja, 32(1), 219-253.

Škrinjarić, T. (2020). Dynamic portfolio optimization based on grey relational analysis approach. Expert Systems with Applications, 147, 1-15.

Šoltés V. ve Nováková B. (2016). Assessment of material living conditions by the means of integrated indices in the VISEGRAD Group. Polish Journal of Management Studies, 13(1), 157-167.

Şafak Uzun, A. M. (2019). Kesişimsellik bağlaminda akademik alanda toplumsal cinsiyet eşitsizliğinin analizi. Doktora Tezi. Ankara: Ankara Üniversitesi.

Türe, H. (2019). OECD ülkeleri için refah ölçümü: Gri ilişkisel analiz uygulaması. Ankara Hacı Bayram Veli Üniversitesi İktisadi ve İdari Bilimler Fakültesi Dergisi, 21(2), 310327.

Üstün, İ. (2011). Toplumsal cinsiyet eşitliği hesaba katabiliyor muyuz? (2. Baskı). Ankara: Uzerler Matbaacilı.

Vargel Pehlivan, P. (2017). Toplumsal cinsiyet bağlamında kuramsal yaklaşımlar: bir literatür taraması. İstanbul Ticaret Üniversitesi Sosyal Bilimler Dergisi, 16(31), 497521. 
Vatandaş, C. (2007). Toplumsal cinsiyet ve cinsiyet rollerinin algilanışı . Istanbul Journal of Sociological Studies , 0 (35) , 29-56.

Wang, P., Zhu, Z. ve Wang, Y. (2016). A novel hybrid MCDM model combining the SAW, TOPSIS and GRA methods based on experimental design. Information Sciences, 345, 27-45.

World Economic Forum (WEF) (2017). Global Gender Gap Report 2017.

World Economic Forum (WEF) (2018). Global Gender Gap Report 2018.

World Economic Forum (WEF) (2020). Global Gender Gap Report 2020.

Yıldırım, B. F. (2015.a). Gri ilişkisel analiz. Yıldırım, B. F ve Önder, E. (Ed.) İşletmeciler, mühendisler ve yöneticiler için operasyonel, yönetsel ve stratejik problemlerin çözümünde çok kriterli karar verme yöntemleri içinde (s. 229-244). Bursa: Dora Yayıncllı.

Yıldırım B. F. (2015.b). Çok kriterli karar verme problemlerinde ARAS yöntemi. Kafkas Üniversitesi İktisadi ve İdari Bilimler Fakültesi (KAÜ İ̈BF) Dergisi, 6(9), 285-296.

Zavadskas, E. K., Kaklauskas, A., Peldschus, F. ve Turskis, Z. (2007). Multi-attribute assessment of road design solutions by using the COPRAS method. Baltic Journal of Road E Bridge Engineering, 2(4), 193-203.

Zavadskas, E. K., Kaklauskas, A. ve Sarka, V. (1994). The new method of multicriteria complex proportional assessment of projects. Technological and Economic Development of Economy, 1(3), 131-139.

Zavadskas, E. K. ve Turskis, Z. (2010). A New Additive Ratio Assessment (Aras) Method in Multicriteria Decision-Making. Technological and Economic Development of Economy, 16(2), 159-172.

\section{Kaynakça Bilgisi / Citation Information}

Yakut. E. ve Kuru, Ö. (2020). AB ülkelerinin küresel cinsiyet ayrımının kadınlar açısından gri ilişkisel analiz, ARAS ve COPRAS yöntemleri ile değerlendirilmesi. OPUS-Uluslararası Toplum Araştırmaları Dergisi, 16(30), 2832-2862. DOI: 10.26466/opus.774845 